University of New Hampshire

University of New Hampshire Scholars' Repository

Faculty Publications

6-22-2010

\title{
Surface and hyporheic transient storage dynamics throughout a coastal stream network
}

\author{
Martin A. Briggs \\ Colorado School of Mines \\ Michael N. Gooseff \\ Pennsylvania State University \\ Bruce J. Peterson \\ Marine Biological Laboratory \\ Kate Morkeski \\ Biological Laboratory, Woods Hole \\ Wilfred M. Wollheim \\ University of New Hampshire, Durham, wil.wollheim@unh.edu
}

See next page for additional authors

Follow this and additional works at: https://scholars.unh.edu/faculty_pubs

Comments

This is an article published by AGU in Water Resources Research in 2010, available online: https://dx.doi.org/10.1029/

2009WR008222

\section{Recommended Citation}

Briggs, M. A., M. Gooseff, B. J. Peterson, K. Morkesk, W. M. Wollheim, and C. S. Hopkinson (2010), Surface and hyporheic transient storage dynamics throughout a coastal stream network, Water Resour. Res., 46, W06516, doi:06510.01029/02009WR008222.

This Article is brought to you for free and open access by University of New Hampshire Scholars' Repository. It has been accepted for inclusion in Faculty Publications by an authorized administrator of University of New Hampshire Scholars' Repository. For more information, please contact Scholarly.Communication@unh.edu. 


\section{Authors}

Martin A. Briggs, Michael N. Gooseff, Bruce J. Peterson, Kate Morkeski, Wilfred M. Wollheim, and Charles S. Hopkinson 


\title{
Surface and hyporheic transient storage dynamics throughout a coastal stream network
}

\author{
Martin A. Briggs, ${ }^{1}$ Michael N. Gooseff, ${ }^{2}$ Bruce J. Peterson, ${ }^{3}$ Kate Morkeski, ${ }^{3}$ \\ Wilfred M. Wollheim, ${ }^{4}$ and Charles S. Hopkinson ${ }^{5}$ \\ Received 19 May 2009; revised 9 November 2009; accepted 14 January 2010; published 22 June 2010.
}

[1] Transient storage of stream water and associated solutes is expected to vary along stream networks in response to related changes in stream hydraulic conditions and morphologic gradients. These spatial changes are relevant to a wide variety of processes (e.g., biogeochemical cycling), yet data regarding these dynamics are limited and almost exclusively confined to the general storage terms of transient storage models with a single-storage zone (1-SZ). We used a transient storage model with two-storage zones (2-SZ) to simulate field data from conservative solute injections conducted in a coastal stream network in Massachusetts to separately quantify surface transient storage (STS) and hyporheic transient storage (HTS). Solute tracer additions were performed at basin-wide, low-flow conditions, and results were compared with respect to stream size. Strong positive relationships with reach contributing area indicated that the size of the main channel and the size and residence time in surface and hyporheic storage zones all increased from small to large streams. Conversely, longitudinal dispersion and the storage zone exchange coefficients had no consistent trends downstream. The influence of storage exchange on median transport time $\left(F_{M E D}^{200}\right)$ was consistently large for STS and negligible for HTS. When compared to 1-SZ model estimates, we found that the general 1-SZ model storage terms did not consistently describe either STS or HTS exchange. Overall our results indicated that many zone-specific (STS and HTS) storage dynamics were sensitive to the combination of hydraulic and morphologic gradients along the stream network and followed positive trends with stream size.

Citation: Briggs, M. A., M. N. Gooseff, B. J. Peterson, K. Morkeski, W. M. Wollheim, and C. S. Hopkinson (2010), Surface and hyporheic transient storage dynamics throughout a coastal stream network, Water Resour. Res., 46, W06516, doi:10.1029/2009WR008222.

\section{Introduction}

[2] To better understand how biogeochemical processes change throughout stream networks, it is critical to determine how transient storage exchange of stream water and solutes varies with stream size because transient storage enhances biogeochemical reactivity of streams. To date, few studies have attempted to identify how stream transient storage relates specifically to location within the stream network, and none has assessed the spatial changes of surface transient storage (STS) (e.g., margins of pools and eddies) and hyporheic transient storage (HTS) independently. Previous findings indicate that a transient storage

\footnotetext{
${ }^{1}$ Hydrologic Science and Engineering Program, Colorado School of Mines, Golden, Colorado, USA.

${ }^{2}$ Department of Civil and Environmental Engineering, Pennsylvania State University, University Park, Pennsylvania, USA.

${ }^{3}$ Ecosystems Center, Biological Laboratory, Woods Hole, Massachusetts, USA.

${ }^{4}$ Institute for the Study of Earth, Oceans, and Space, University of New Hampshire, Durham, New Hampshire, USA.

${ }^{5}$ Department of Marine Sciences, University of Georgia, Athens, Georgia, USA.
}

Copyright 2010 by the American Geophysical Union. 0043-1397/10/2009WR008222 model that accounts for a single-storage zone (1-SZ) can have unequal sensitivity to STS and HTS exchange based on discharge and stream morphology, often making these modeling results difficult to interpret [Harvey and Wagner, 2000; Edwardson et al., 2003]. Thus, any comparison of two-storage zone (2-SZ) model parameters to previous work based on a 1-SZ model are hampered by the latter's aggregation of all storage exchange into one general compartment. Additionally, biogeochemical processing within STS and HTS is very different as factors such as residence time, redox condition, carbon storage, sediment contact, and insolation vary strongly between surface and subsurface storage zones.

[3] Transient storage exchange dynamics should be a function of stream size because many processes that drive exchange are strongly governed by channel morphology [Harvey and Bencala, 1993; Gooseff et al., 2007; Battin et al., 2008], which often transitions longitudinally along the stream network from higher gradient erosional zones to lower gradient depositional zones [Leopold et al., 1964; Schumm, 1977; Montgomery and Buffington, 1997]. This channel morphology is strongly related to basin type and can be affected by land use, which influences fluvial geomorphic complexity [Gooseff et al., 2007]. Therefore, as stream morphology changes with stream order we can 


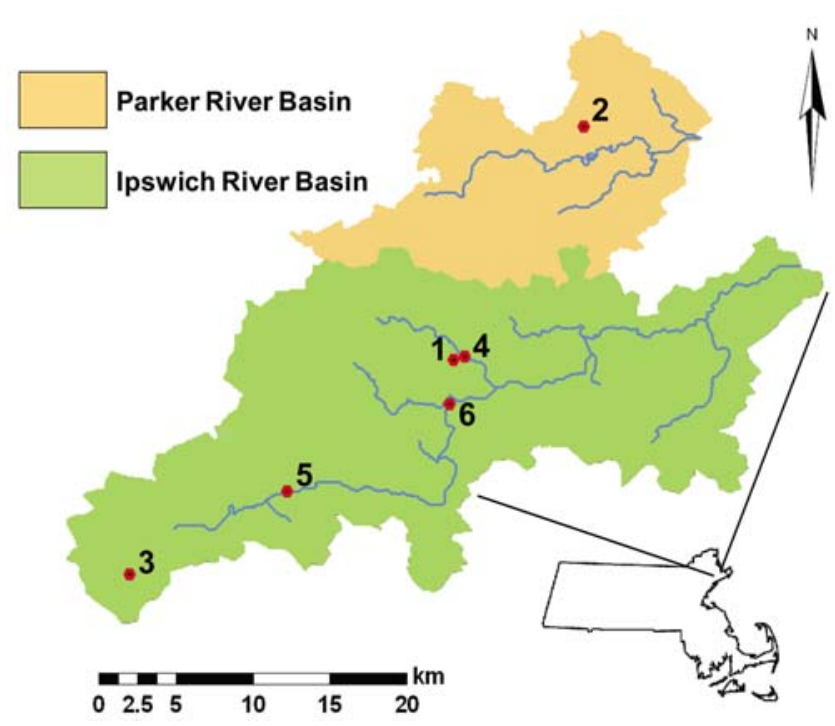

Figure 1. The Ipswich River and Parker River basins in Massachusetts. Both coastal watersheds drain east into the salt marshes of Plum Island Sound. Study locations are labeled from the smallest to the largest contributing area as (1) Lockwood Brook, (2) Cart Creek, (3) Sawmill Brook, (4) Fish Brook, (5) Ipswich River \#1, and (6) Ipswich River \#2.

expect shifts in transient storage dynamics as well. For example, HTS exchange in a low-gradient, fifth-order stream in Oregon, was influenced by a broader suite of morphologic features, such as meanders, channel splits, and island bars, than HTS exchange in steep headwater streams in the same basin dominated by step-pool sequences [Kasahara and Wondzell, 2003]. Similarly the mechanisms of STS (i.e., retention in pools, behind debris dams and boulders, along shallow channel margins, and within vegetation) should vary along the stream network with gradients in morphology, hydraulics, and land use.

[4] Although their results conflict somewhat, many studies conducted using the 1-SZ model have indicated that transient storage may become less influential to transport and in-stream processes as stream size increases. A synthesis of published data from 246 tracer experiments across a variety of climates from first-order through sixth-order streams found that both mean storage residence time and storage zone size normalized to the corresponding main channel area $\left(A_{S} / A\right)$ decreased with greater stream size [Battin et al., 2008], though the authors note that interpretation of these results is hindered by an inability to distinguish between STS and HTS exchange. A comparison of first-order through fifth-order streams across Appalachian and Cascade mountain streams showed that $A_{S} / A$ ratios generally decreased from small to large streams when higher order reaches are constrained by valley morphology but increased when fifth-order reaches were unconstrained due to a wide valley floor [D'Angelo et al., 1993]. This indicates that basin morphology can exert a strong influence on transient storage and that spatial trends may be specific to basin type. Conversely, another study of first-order through fifthorder streams found no significant relationship between $A_{S} / A$ and river size [Edwardson et al., 2003]. As all of these results were generated using models that aggregated the affects of STS and HTS exchange on solute transport, the discrimination of STS from HTS may clarify trends in transient storage dynamics with increasing stream size and yield vital new information on how stream systems function on the basin scale.

[5] The relationship between stream size and biogeochemical processes is also not well defined. Several studies have indicated that larger streams may not be as efficient at retaining nutrients as their headwaters [i.e., Valett et al., 1996; Alexander et al., 2000; Bernot and Dodds, 2005], although it has been hypothesized that nitrogen uptake has been underestimated in large streams by using a single solute travel time and/or common spatial model aggregation techniques [Lindgren and Destouni, 2004; Darracq and Destouni, 2005]. Some large streams probably remove much higher proportions of upstream nitrogen inputs than headwater streams simply because they are much longer [Wollheim et al., 2006], and, whereas large streams can respond to moderate increases in nitrogen loading by increasing removal, nitrogen removal efficiency in headwater streams declines with increased nitrogen loading [Mulholland et al., 2008]. Additionally, as streams widen and canopy cover over the channel declines, high light availability can promote the growth of aquatic plants and microbes that cycle nutrients [Vannote et al., 1980; Battin et al., 2008]. Thus, STS may be particularly important to biogeochemical processes in larger streams where photomediated processes would have more opportunity to influence stream water concentrations.

[6] To augment our limited understanding of spatial changes in zone-specific transient storage dynamics, we applied a 2-SZ transient storage model to streams of varying size under summer flow conditions within a coastal stream network. We measured stream reach velocity distributions to initially constrain model estimates of the main channel (MC) and STS size, and we optimized model simulations to fit solute breakthrough curves (BTCs) collected within the MC and STS zones. This approach reduces the potential for model bias toward fast exchange processes that can result from using the 1-SZ model and MC solute data alone during the optimization process and yields independent estimates of STS and HTS exchange dynamics [see Briggs et al., 2009]. We compare these results with those of a 1-SZ model to determine if the lumped storage parameters consistently describe either STS or HTS exchange throughout the stream network. The main objective of this study is to evaluate optimized STS and HTS parameter sets and transient storage metrics as a function of reach contributing area to identify longitudinal relationships along the stream continuum under low-flow conditions. These relationships can provide valuable insight into the interaction between river size and storage zone biogeochemical activity during base flow conditions.

\section{Site Description}

[7] The Ipswich River watershed in northeastern Massachusetts drains $404 \mathrm{~km}^{2}$ of mixed forest and urban and agricultural land into the Plum Island Sound estuary (Figure 1). The surficial geology of the Ipswich basin is dominated by glacial deposits [Carlozzi et al., 1975]. All experimental reaches were within the Ipswich River watershed except for the second-order Cart Creek reach, which was located in the smaller adjacent Parker River basin, a 
Table 1. Physical Characteristics and Morphology of Experimental Reaches Along with the Locations of Specific STS Zones Monitored During Solute Injections ${ }^{\mathrm{a}}$

\begin{tabular}{|c|c|c|c|c|c|c|c|c|c|}
\hline Reach & $\begin{array}{l}\text { Length } \\
\text { (m) }\end{array}$ & Order & $\begin{array}{l}\text { Contr. Area } \\
\left(\mathrm{km}^{2}\right)^{\mathrm{a}}\end{array}$ & Slope & $\begin{array}{l}\text { Mean } w \\
\quad(\mathrm{~m})\end{array}$ & $\begin{array}{l}\text { Mean } d \\
(\mathrm{~m})\end{array}$ & $\begin{array}{c}\text { Channel } \\
\text { Morphology }\end{array}$ & $\begin{array}{c}\text { Dominant } \\
\text { Reach STS }\end{array}$ & $\begin{array}{c}\text { Distance to STS } \\
\text { From Reach Head (m) }\end{array}$ \\
\hline Lockwood Brook & 219 & 1 & 1.1 & 0.0220 & 1.5 & 0.05 & step pool; plane bed & $\begin{array}{l}\text { channel margin, pool } \\
\text { channel margin, run, }\end{array}$ & $50.0,111.0,180.0$ \\
\hline Cart Creek & 213 & 2 & 2.8 & 0.0077 & 2.2 & 0.13 & pool riffle & macrophyte bed & $63.0,166.0$ \\
\hline Sawmill Brook & 260 & 2 & 4.0 & 0.0171 & 1.9 & 0.09 & pool riffle & channel margin, run, pool & $39.0,44.0,140.0$ \\
\hline Fish Brook & 450 & 3 & 37.7 & 0.0023 & 6.6 & 0.23 & $\begin{array}{l}\text { pool riffle; dune ripple } \\
\text { regime channel; }\end{array}$ & channel margin, back eddy & $86.0,186.0,396.0$ \\
\hline Ipswich River \#1 & 547 & 4 & 93.6 & 0.0005 & 7.3 & 0.44 & meandering channel & $\begin{array}{l}\text { woody debris, back eddy } \\
\text { macrophyte bed, large }\end{array}$ & $346.0,463.0$ \\
\hline Ipswich River \#2 & 616 & 5 & 187.7 & 0.0004 & 15.3 & 0.56 & meandering channel & backwater & $0.0,200.0,460.0$ \\
\hline
\end{tabular}

${ }^{\mathrm{a} C}$ Contributing area estimated from digital elevation model of the basin.

watershed with similar land use and network characteristics (Figure 1, Table 1). Additional attributes of various study reaches and solute injection experiments are contained in Tables 1 and 2.

\section{Methods}

[8] To assess STS and HTS dynamics independently for each study reach model simulations of conservative tracer $\mathrm{NaCl}$ additions were conducted using a 2-SZ version of the 1-D solute transport model OTIS [Runkel, 1998; Choi et al., 2000; Gooseff et al., 2004] for which the governing equations are

$$
\begin{array}{r}
\frac{\partial C}{\partial t}=-\frac{Q}{A} \frac{\partial C}{\partial x}+\frac{1}{A} \frac{\partial}{\partial x}\left(A D \frac{\partial C}{\partial x}\right)+\frac{q_{L}}{A}\left(C_{L}-C\right) \\
+\alpha_{S T S}\left(C_{S T S}-C\right)+\alpha_{H T S}\left(C_{H T S}-C\right), \\
\frac{\partial C_{H T S}}{\partial t}=\alpha_{H T S} \frac{A}{A}{ }_{H T S}\left(C-C_{H T S}\right), \\
\frac{\partial C_{S T S}}{\partial t}=\alpha_{S T S} \frac{A}{A_{S T S}}\left(C-C_{S T S}\right) .
\end{array}
$$

where $t$ is time; $x$ is distance downstream; $C, C_{\mathrm{STS}}, C_{\mathrm{HTS}}$ and $C_{\mathrm{L}}$ are solute concentrations in the MC, STS, HTS, and groundwater $\left(\mathrm{M} / \mathrm{L}^{3}\right) ; Q$ is the in-stream volumetric flow rate $\left(\mathrm{L}^{3} / \mathrm{T}\right) ; q_{L}$ is the groundwater inflow rate $\left(\mathrm{L}^{3} / \mathrm{T} / \mathrm{L}\right) ; D$ is the $\mathrm{M} C$ longitudinal dispersion coefficient $\left(\mathrm{L}^{2} / \mathrm{T}\right) ; A, A_{S T S}$, and $A_{\mathrm{HTS}}$ are the cross-sectional areas of the MC, STS, and HTS, respectively $\left(\mathrm{L}^{2}\right) ; \alpha_{\mathrm{STS}}$ and $\alpha_{\mathrm{HTS}}$ are the exchange coefficients between MC and STS and HTS, respectively $(1 / T)$. Model parameter symbols, units and definitions are listed in Table 3 .

[9] As additional storage parameters are added to the original 1-SZ OTIS model [Runkel, 1998], additional data beyond the boundary $\mathrm{MC}$ solute BTCs regarding those parameters must be obtained to maintain parameter sensitivity and avoid nonunique parameter estimates in the 2-SZ model. We used reach velocity distributions and solute BTC data collected in reach representative STS zones and adjacent MC locations to increase the information content of the parameter estimation process; this method is detailed by Briggs et al. [2009]. In summary, a survey of downstream velocity patterns was used to generate initial estimates of both the MC and STS cross-sectional areas by delineating reach averaged areas of flowing water and in-channel storage based on a $0.01 \mathrm{~m} / \mathrm{s}$ division. These surveys served the dual purpose of defining reach averaged $A$ and $A_{\mathrm{STS}}$ estimates based on physical measurement, which were used as initial parameter constraints, and identifying reach representative STS zones that were monitored during the solute injections.

[10] The exchange process between the MC and STS can be very complicated [Weitbrecht et al., 2008], but fundamentally the MC BTC serves as the input signal to an adjacent STS zone. General information regarding this process is contained in the modification of the tracer signal, or differences in concentration with time, between the $\mathrm{MC}$ and adjacent STS locations. This differential pattern is specific to each STS zone, but when these patterns are collected from reach representative zones and aggregated, this collective information can be used directly to inform reach representative STS model parameters. For most experiments three sets of MC/STS concentration differentials were collected. Three sets were a practical limitation based on a reasonable number of solute probes and data loggers. Although the choices of which STS zones to instrument during the experiments were subjective, this process was strongly aided by the velocity survey, which identified dominant transient storage zones along the reach. These

\begin{tabular}{|c|c|c|c|c|c|c|}
\hline Reach & Date & $\begin{array}{l}\text { Duration } \\
\text { (h) }\end{array}$ & $\begin{array}{c}\text { Rate } \\
(\mathrm{mL} / \mathrm{min})\end{array}$ & $\begin{array}{l}\text { Concentration } \\
(\mathrm{g} \mathrm{NaCl} / \mathrm{L})\end{array}$ & $\begin{array}{l}\text { Mean } Q \\
(\mathrm{~L} / \mathrm{s})\end{array}$ & $\begin{array}{c}\text { Med. Reach } \\
\text { Travel Time (h) }\end{array}$ \\
\hline Lockwood Brook & $7 / 13 / 2007$ & 6.68 & 63.0 & 100 & 2.0 & 2.27 \\
\hline Cart Creek & $6 / 22 / 2007$ & 6.13 & 150.0 & 200 & 10.8 & 1.88 \\
\hline Sawmill Brook & $7 / 17 / 2007$ & 6.75 & 180.0 & 200 & 6.3 & 2.60 \\
\hline Fish Brook & $7 / 02 / 2008$ & 4.25 & 2000.0 & 200 & 126.0 & 1.95 \\
\hline Ipswich River \#1 & $7 / 26 / 2007$ & instant & N/A & 200 & 46.0 & 8.35 \\
\hline Ipswich River \#2 & $8 / 09 / 2007$ & instant & N/A & 200 & 239.0 & 9.18 \\
\hline
\end{tabular}
additional field measurements help to inform the 2-SZ modeling by providing data regarding $A, A_{\mathrm{STS}}$, and $\alpha_{\mathrm{STS}}$,

Table 2. Solute Injection Details for Each Experiment 
Table 3. Model Parameters, Storage Metrics and Acronyms Referred to Throughout the Article

\begin{tabular}{|c|c|}
\hline Symbol/Units & Description \\
\hline \multicolumn{2}{|c|}{ Model Parameters } \\
\hline & Main channel longitudinal \\
\hline$D\left(\mathrm{~m}^{2} \mathrm{~s}^{-1}\right)$ & $\begin{array}{l}\text { dispersion coefficient } \\
\text { Main }\end{array}$ \\
\hline $\begin{array}{l}A\left(\mathrm{~m}^{2}\right) \\
A_{S}\left(\mathrm{~m}^{2}\right)\end{array}$ & $\begin{array}{l}\text { Main channel cross-sectional area } \\
\text { Storage zone cross-sectional area }\end{array}$ \\
\hline$\alpha\left(\mathrm{s}^{-1}\right)$ & Storage zone exchange coefficient \\
\hline \multicolumn{2}{|c|}{ Model Storage Metrics } \\
\hline & $\begin{array}{l}\text { Percentage which median transport } \\
\text { time is increased by exchange } \\
\text { with storage, normalized }\end{array}$ \\
\hline$F_{M E D}^{200}(\%)$ & to a $200 \mathrm{~m}$ reach \\
\hline$T_{\text {STO }}(\mathrm{h})$ & Mean storage zone residence time \\
\hline$q_{S}\left(\mathrm{~m}^{2} \mathrm{~s}^{-1}\right)$ & $\begin{array}{l}\text { Storage exchange flux } \\
\text { per meter stream length }\end{array}$ \\
\hline & $\begin{array}{l}\text { Damköhler number, } \\
\text { evaluates experimental } \\
\text { reach length based on the } \\
\text { relationship of storage }\end{array}$ \\
\hline DaI & exchange to advective transport \\
\hline \multicolumn{2}{|c|}{ Commonly Used Acronyms } \\
\hline $\mathrm{MC}$ & Main channel \\
\hline STS & $\begin{array}{l}\text { Surface transient storage } \\
\text { (used in subscript for zone } \\
\text { specific variables) }\end{array}$ \\
\hline HTS & $\begin{array}{l}\text { Hyporheic transient storage } \\
\text { (used in subscript for zone } \\
\text { specific variables) }\end{array}$ \\
\hline BTC & Solute tracer break-through curve \\
\hline CSS & Composite scaled sensitivity \\
\hline
\end{tabular}

Note: The designation STS or HTS is added to each zone-specific 2-SZ model parameter and storage metric to distinguish between surface and hyporheic transient storage.

thereby avoiding potential issues of equifinality and overparameterization in our simulation process.

[11] Simulations of both the MC BTC and reach averaged MC/STS differential pattern were optimized through nonlinear regression with UCODE_2005 during the 2-SZ modeling process [Poeter et al., 2005; Hill and Tiedman, 2007]. As HTS specific size and solute data were not collected, these parameters were optimized to improve both the $\mathrm{MC}$ and STS BTC simulations, which is analogous to how the general storage terms are estimated during the 1-SZ modeling process for which only MC BTC data were used; 1-SZ simulations were also optimized using UCODE_2005.

[12] Dissolved $\mathrm{NaCl}$ was added via continuous injections in the four smallest stream reaches and as pulse additions in the two main stem reaches. Constant rate and pulse additions have been found to yield similar information regarding reach-scale residence time distributions [Payn et al., 2008] and are therefore comparable, although constant rate additions have been shown to provide greater parameter sensitivity in transient storage model simulations in some cases [Wagner and Harvey, 1997]. Our study reach lengths were $>20$ bankfull widths, and the appropriateness of these reach length selections was assessed by evaluating the Damköhler number (DaI) [Wagner and Harvey, 1997]:

$$
D a I=\frac{\alpha\left(1+A / A_{S}\right) L}{u},
$$

where $L$ is the reach length $(\mathrm{m})$ and $u$ is average stream velocity $(\mathrm{m} / \mathrm{s})$. The highest sensitivity to model storage parameters occurs within a DaI range of $0.1-10$, and this metric was applied to STS, HTS, and 1-SZ storage parameters individually.

[13] Velocity transect measurements were made normal to flow approximately every two bankfull widths with a topsetting wading rod equipped with an electromagnetic velocity meter (Marsh-McBirney model Flomate 2000) or a handheld acoustic Doppler velocimeter (FlowTracker ADV). The Marsh-McBirney meter had a resolution of $0.01 \mathrm{~m} / \mathrm{s}$, while the FlowTracker ADV resolution was $0.0001 \mathrm{~m} / \mathrm{s}$. Velocity values of $<0.01 \mathrm{~m} / \mathrm{s}$ were interpreted as STS for all velocity transects, and mean reach $w$ and $d$ was determined from these surveys. A Trutrack WT-HR water level rod was deployed prior to each experiment to record stage changes. Mean reach slope $(S)$ was determined as the change in water surface elevation over the reach divided by the reach length. Discharge at the head and end of each reach was estimated through dilution gauging and/or wading method techniques. In-stream solute concentrations during injection experiments were monitored by a combination of handheld temperature-correcting YSI EC 300 and YSI 60 probes and Campbell Scientific 547A conductivity probes with Campbell Scientific data loggers. Probes were usually attached to rebar at $\sim 60 \%$ depth. Specific conductivity above background was converted to concentration of $\mathrm{NaCl}$ through a measured relationship between standards of known concentration (ranging from 0 to $500 \mathrm{mg} \mathrm{NaCl} / \mathrm{L}$ ) and resultant conductivity determined for each probe using water from the study reach [Gooseff and McGlynn, 2005].

[14] When optimizing parameter estimates, the criteria for model convergence was set at the UCODE_2005 default, which is $<1 \%$ change in parameter values between iterations [Poeter et al., 2005]. For some experimental reach models, simultaneous convergence of all model parameters using this criterion was not possible because of high correlation and low sensitivity of some parameters (typically HTS). Therefore, varying sets of parameter values were left open to estimation and converged, while others remained fixed until all parameters converged under the $<1 \%$ change criterion. When the weighted least squares objective function displayed little change, sensitivity, correlation, and 95\% confidence interval (CI) analyses were performed for all parameters simultaneously using the UCODE_2005 sensitivity analysis mode. Composite scaled sensitivities (CSS) were used to assess whether there was sufficient information provided by the observations (i.e., the lower reach boundary MC BTC and the average MC/STS differential pattern) to support the estimation of each parameter. Parameters that have a CSS below $1.0 \mathrm{and} /$ or are more than two orders of magnitude less sensitive than the most sensitive parameter in the simulation may be difficult to estimate accurately [Hill and Tiedman, 2007].

[15] Transient storage metrics were calculated to assess the importance of STS and HTS exchange to solute transport and nutrient retention. Definitions of the metrics used for this analysis are listed below and in Table 3. The ratio of storage zone cross-sectional area to MC cross-sectional area $\left(A_{S} / A\right)$ was used for intersite comparison among streams of disparate size [D'Angelo et al., 1993]. The mean storage 


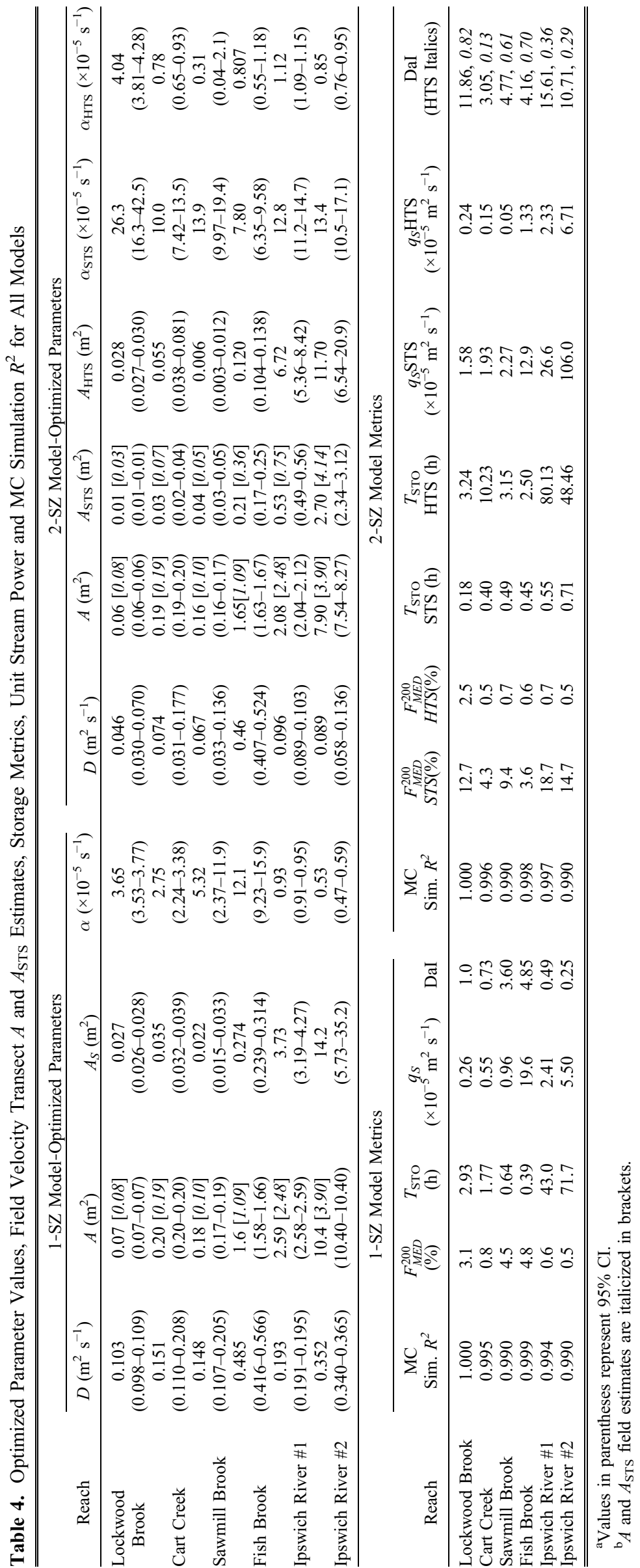


Table 5. CSS of All Model Parameters ${ }^{\mathrm{a}}$

\begin{tabular}{lcccccc}
\hline & \multicolumn{6}{c}{ Composite Scaled Sensitivity } \\
\cline { 2 - 7 } \multicolumn{1}{c}{ Simulation } & $D$ & $A$ & $A_{\mathrm{STS}}$ & $A_{\mathrm{HTS}} / A_{\mathrm{S}}$ & $\alpha_{\mathrm{STS}}$ & $\alpha_{\mathrm{HTS}} / \alpha$ \\
\hline Lockwood Brook & $0.8 / 2.6$ & $32.5 / 48.6$ & 4.9 & $3.9 / 5.4$ & 1.4 & $4.6 / 6.0$ \\
Cart Creek & $0.1 / 0.2$ & $8.9 / 9.9$ & 0.2 & $0.2 / 0.7$ & 0.9 & $0.4 / 0.6$ \\
Sawmill Brook & $0.3 / 0.6$ & $12.4 / 14.1$ & 2.8 & $0.1 / 13.0$ & 1.2 & $0.2 / 0.6$ \\
Fish Brook & $1.4 / 1.7$ & $34.9 / 41.0$ & 3.8 & $0.7 / 5.6$ & 2.1 & $0.9 / 2.3$ \\
Ipswich River \#1 & $2.0 / 5.3$ & $30.1 / 60.4$ & 6.3 & $0.2 / 0.4$ & 2.7 & $2.5 / 3.3$ \\
Ipswich River \#2 & $0.3 / 1.5$ & $8.7 / 1.2$ & 2.5 & $0.1 / 0.1$ & 1.1 & $0.6 / 0.5$ \\
\hline
\end{tabular}

Note: The 1-SZ CSS are generally larger than their 2-SZ counterparts, although the storage terms are not directly comparable.

${ }^{\mathrm{a}}$ General $1-\mathrm{SZ}$ terms are listed in italics.

zone residence time $\left(T_{\mathrm{STO}}\right)$ was determined for both STS and HTS independently as [Thackston and Schnelle, 1970]:

$$
T_{S T O}=\frac{A_{S}}{\alpha A} .
$$

Similarly the storage exchange flux per meter stream length $\left(q_{S}\right)$ was calculated as $\alpha A$, or the denominator of equation 5 [Harvey et al., 1996]. Finally the fraction of median transport time due to storage $\left(F_{\mathrm{MED}}\right)$ was determined as [Runkel, 2002]

$$
F_{M E D}=\frac{t_{M E D}-t_{M E D}^{m}}{t_{M E D}}
$$

where $t_{\mathrm{MED}}$ is the median reach travel time determined from the lower boundary MC BTC simulation with transient storage exchange and $t_{M E D}^{m}$ is the median travel time calculated from the lower boundary MC BTC simulation without transient storage exchange (i.e., $\alpha=0$ ). The median travel time in each case was determined as the time to reach half of the plateau solute concentration for a constant rate addition, and as the time of center mass of the solute BTC for an instantaneous slug. To remove the effects of reach length on transport time, $L=200 \mathrm{~m}$ (i.e., $F_{M E D}^{200}$ ) was chosen for all $F_{\mathrm{MED}}$ simulations [Runkel, 2002].

[16] Mean stream reach dimensions, transient storage parameters and transient storage metrics were compared directly across stream size to identify trends along the stream network. Stream size in this case was assumed to be a direct function of the contributing area to that point [Wolman and Leopold, 1957; Leopold et al., 1964], and this area was determined for the downstream end of each stream reach based on a digital evaluation model (DEM) analysis with ArcViewGIS software using 1:5000 contours and 1:25,000 hydrography features. A preliminary review indicated that many data sets showed spatial trends as a function of contributing area, and these relationships were best described by a linear or power law function. A power law function with an exponent of 1.0 is linear; therefore, power laws were fit to all data sets that appeared to exhibit a trend, and any function with an exponent of 1.0 within the exponent $95 \%$ confidence interval was assumed to be comparably described by a linear function. Each function was optimized to yield the lowest sum of squared residuals (SOSR) to the data in question. Data fits were evaluated by the distribution of residuals and the coefficient of determination $\left(R^{2}\right)$ as

$$
R^{2}=1-\left(\frac{S O S R}{S O S R_{T}}\right)
$$

where $\operatorname{SOSR}_{T}$ is the sum of squared residuals between each data point and the mean of that data set. The $R^{2}$ evaluation of 1.0 indicates a "perfect fit" to the data, and this metric was also used to evaluate the MC simulations of the both the 1-SZ and 2-SZ models.

\section{Results}

[17] Solute transport model fits to observed $M C$ data were good $\left(R^{2} \geq 0.99\right)$ and the fits of corresponding $1-S Z$ and 2-SZ models were similar (Table 4). Examples from Lockwood Brook and Ipswich River \#2 were presented in detail by Briggs et al. [2009]. Field-estimated $A$ and $A_{\mathrm{STs}}$ values, optimized parameter values for each injection with $95 \%$ confidence intervals, and transient storage metrics are reported in Table 4, and the CSS for optimized parameters are reported in Table 5. A DaI assessment was applied to both the 1-SZ and 2-SZ models, and all stream lengths chosen resulted in optimal transient storage parameter sensitivity (i.e., $\mathrm{DaI}=$ 0.1-10) except for STS in Fish Brook and the main stem (Ipswich River) reaches, where DaI estimates exceeded 10.

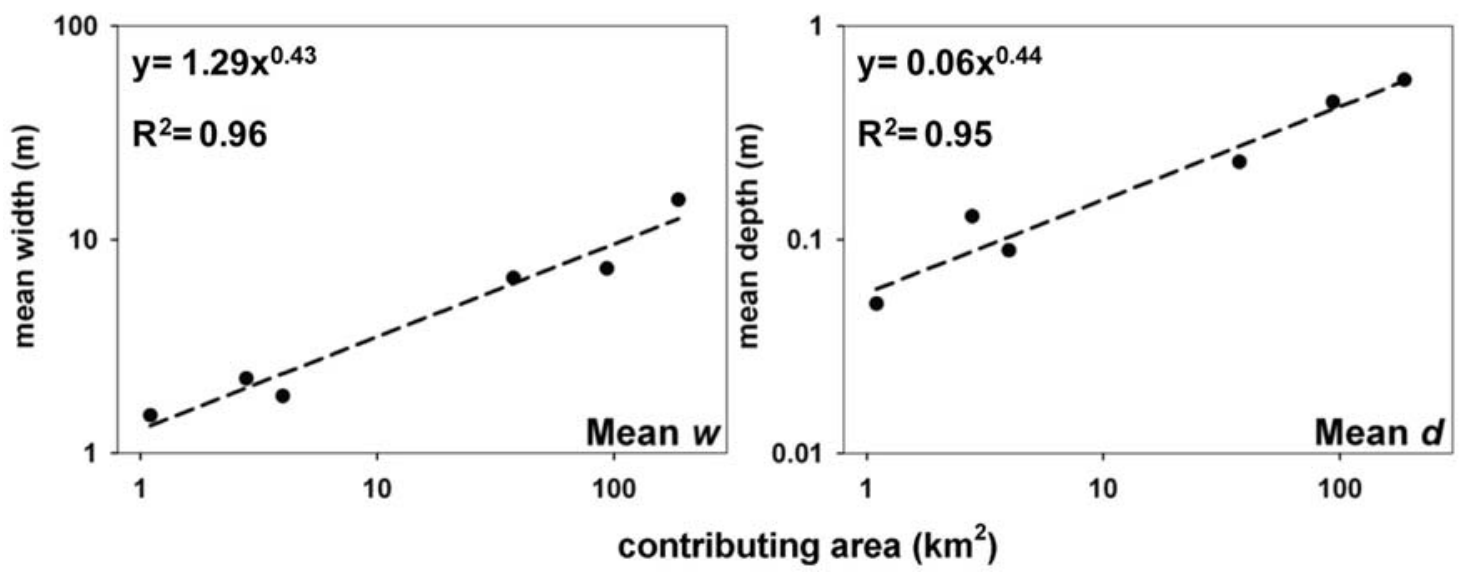

Figure 2. Mean channel dimensions of experimental reaches in the Ipswich and Parker River basins as a function of contributing area. Optimal power law regressions are indicated by the dashed lines. 

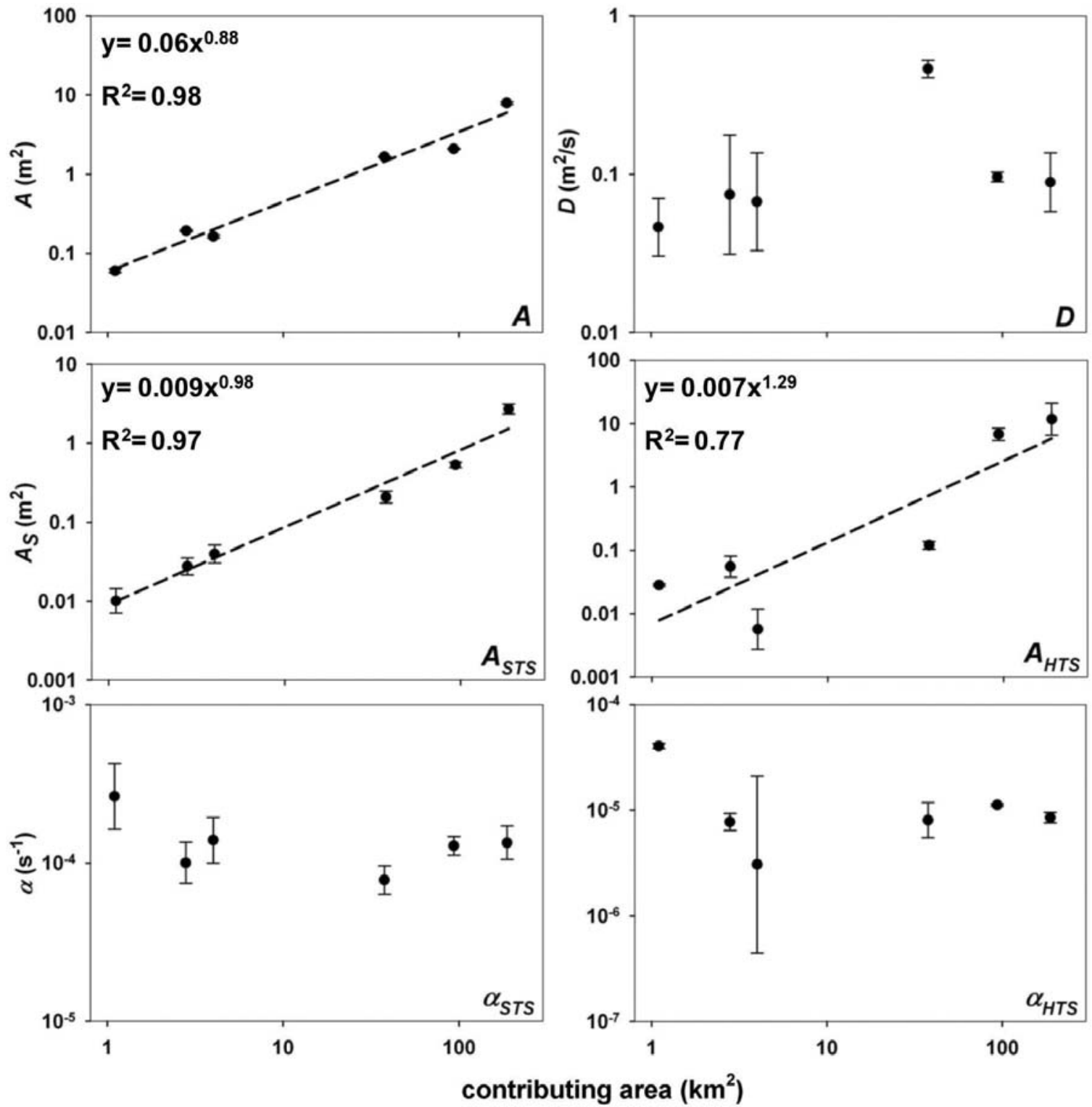

Figure 3. Trends in model parameters with contributing area varied from nonexistent to fairly positive (parameter $95 \% \mathrm{CI}$ in brackets). All three parameters showing trends $\left(A, A_{\mathrm{STS}}, A_{\mathrm{HTS}}\right)$ were well described with a power law regression (dashed line) with an exponent close to 1.0 , indicating a linear relationship.

Notably, the corresponding HTS DaI for these experiments were all $<1$. Both reach-averaged $w$ and $d$ showed strong increasing relationships with contributing area that were best described by power law functions (Figure 2).

\subsection{2-SZ Model Results}

[18] Dispersion coefficient $(D)$ : Longitudinal dispersion values were generally small for all reaches, ranging from $0.046 \mathrm{~m}^{2} \mathrm{~s}^{-1}$ for Lockwood Brook to $0.46 \mathrm{~m}^{2} \mathrm{~s}^{-1}$ for Fish Brook, and did not exhibit a trend with contributing area (Figure 3). Though many estimates of CSS were below 1.0, they were always within two orders of magnitude of the highest value in the parameter set. The $95 \%$ confidence intervals were relatively large in most simulations; the interval was greater than the estimated value for Cart Creek and Sawmill Brook, the two reaches with the lowest CSS for this parameter.
[19] MC cross-sectional area (A): Optimized values of $A$ increased with contributing area, a relationship that was fit with a power law function to the 0.88 power $\left(R^{2}=0.98\right)$ and unbiased residuals (Figure 3 ). The $95 \%$ confidence interval around the power law exponent $( \pm 0.19)$ included 1.0 , indicating a linear function could provide a similar fit to the data. The smallest and largest $A$ corresponded to streams with the smallest and largest contributing areas, respectively, with an optimized $A$ of $0.06 \mathrm{~m}^{2}$ for Lockwood Brook and $7.9 \mathrm{~m}^{2}$ for Ipswich River \#2. Estimates of $A$ had the narrowest $95 \%$ confidence intervals of all estimated parameters. The final calculated CSS for $A$ was highest of all parameters in every simulation (avg. 21.4), ranging from 8.85 for Cart Creek to 34.88 for Fish Brook. Optimized $A$ values agreed well with the field-estimated values from the velocity transect surveys for all reaches except for Ipswich River \#2. 


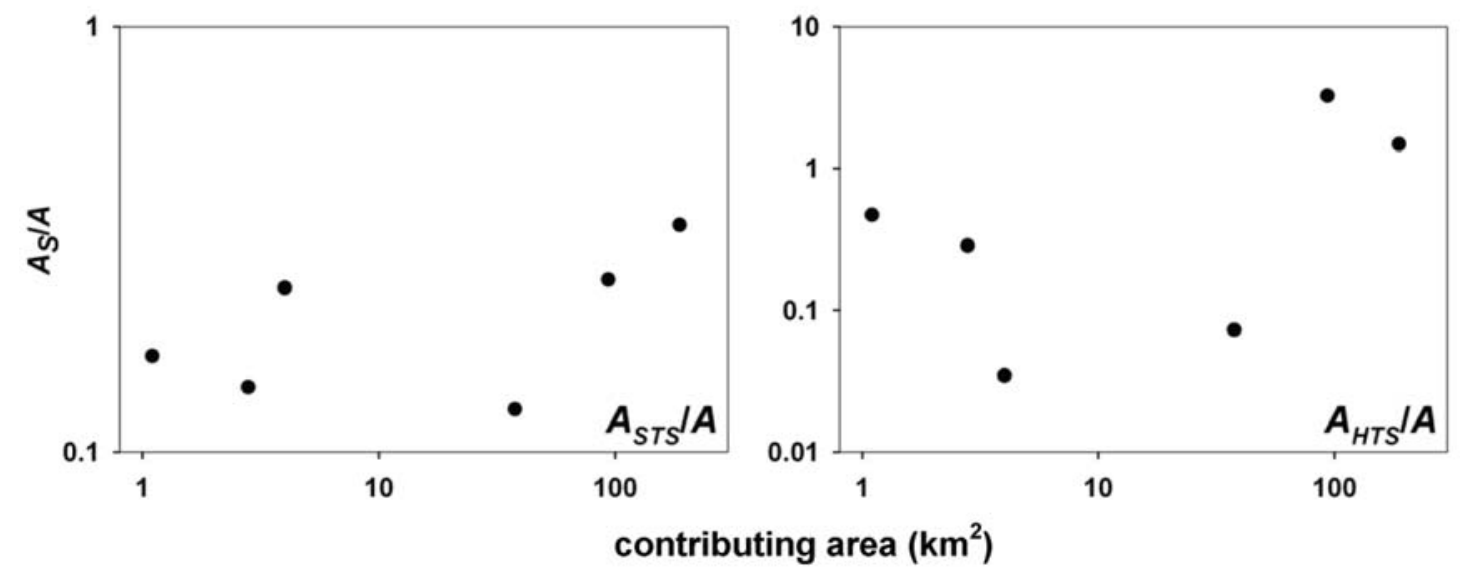

Figure 4. The ratio of storage zone area to $M C$ area was highly variable for HTS, though neither storage compartment ratio showed a consistent decrease downstream as been found in previous work; the main stem reaches had the largest storage zone relative to the MC for both STS and HTS.

[20] STS cross-sectional area $\left(A_{S T S}\right)$ : Optimized values of $A_{S T S}$ also showed a strong positive relationship with contributing area and were best fit as a power law function with a power of $0.98\left(R^{2}=0.97\right)$, indicating an approximately linear relationship (Figure 3 ). The smallest and largest $A_{\mathrm{STS}}$ corresponded to Lockwood Brook $\left(0.01 \mathrm{~m}^{2}\right)$ and Ipswich River \#2 $\left(2.7 \mathrm{~m}^{2}\right)$, respectively. The $95 \%$ confidence intervals of $A_{\mathrm{STS}}$ estimates were relatively tight, ranging from $13 \%$ of the estimated value for Ipswich River \#1 to $55 \%$ of the estimated value for Sawmill Brook. CSS values for $A_{\text {STS }}$ had the second highest average of the estimated parameters (mean 3.4), and ranged from 0.17 for Cart Creek to 6.31 at Ipswich River \#1. Final optimized $A_{\text {STS }}$ values agreed well with the field-estimated values generated from velocity transect measurements for most simulations except Lockwood Brook.

[21] HTS cross-sectional area $\left(A_{\mathrm{HTS}}\right)$ : The optimized $A_{\text {HTS }}$ values had a weak positive trend with contributing area (Figure 3), that were best fit by a power law function with exponent $1.29\left(R^{2}=0.77\right.$, unbiased distribution of residuals). The power law exponent had a large $95 \%$ confidence interval of \pm 0.98 , indicating this fit could also be described by a linear function. Optimized values of $A_{\mathrm{HTS}}$ had a broad range from $0.006 \mathrm{~m}^{2}$ for Sawmill Brook to $12.0 \mathrm{~m}^{2}$ for Ipswich River \#2. Average CSS for all simulations was the lowest of all estimated parameters (0.84), leveraged greatly by that of Lockwood Brook (CSS of 3.87). The CSS values determined for Sawmill Brook, Ipswich River \#1 and Ipswich River \#2 were more than two orders of magnitude lower than the corresponding value for $A$. Consequently the $95 \%$ confidence interval estimates were variable, being small for Lockwood Brook and Fish Brook, but larger than the magnitude of the estimated parameter for Sawmill Brook and Ipswich River \#2.

[22] STS/HTS cross-sectional area normalized to the MC $\left(A_{s} / A\right)$ : Reach-specific $A_{\mathrm{STS}}$ values normalized to the corresponding $A$ had a fairly narrow range of 0.13 for Fish Brook to 0.34 for Ipswich River \#2, with the largest values found for the main stem reaches (Figure 4). The values of $A_{\mathrm{HTS}} / A$ were much more variable, ranging from 0.03 at Sawmill Brook to 3.23 at Ipswich River \#1, but again was highest for the two main stem experiments.
[23] STS exchange coefficient ( $\left.\alpha_{\mathrm{STS}}\right)$ : Optimized values of $\alpha_{\text {STS }}$ were consistent across stream size, ranging from $7.8 \times$ $10^{-5} \mathrm{~s}^{-1}$ for Fish Brook to $2.63 \times 10^{-4} \mathrm{~s}^{-1}$ for Lockwood Brook (Figure 3). The 95\% confidence intervals were all fairly small for this parameter, with none of the intervals exceeding the parameter values. CSS values were generally high compared to other parameters, with only the Cart Creek value less than 1.0.

[24] HTS exchange coefficient ( $\left.\alpha_{\mathrm{HTS}}\right)$ : Optimized values of $\alpha_{\text {HTS }}$ were also fairly consistent with the exception of Lockwood Brook $\left(4.04 \times 10^{-5} \mathrm{~s}^{-1}\right)$, which had an exchange coefficient that was 13 times larger than the lowest value in the set $\left(3.10 \times 10^{-6} \mathrm{~s}^{-1}\right)$ determined for Sawmill Brook (Figure 3). The 95\% confidence intervals were narrow for every reach except for Sawmill Brook, which had an interval more than six times larger than the estimated parameter. This uncertain parameter estimate also had the lowest CSS of 0.15 . The average CSS was the same as that of $\alpha_{S T S}$, and this statistic was inflated by the relatively high sensitivity determined for the Lockwood Brook $\alpha_{H T S}$ (CSS of 4.55).

[25] Fraction of median transport time due to storage $\left(F_{M E D}^{200} S T S, F_{M E D}^{200} H T S\right)$ : There was a large difference in the influence of STS and HTS exchange on median transport time (Figure 5). STS exchange increased transport time considerably for most models, ranging from $3.6 \%$ for Fish Brook to $19 \%$ for Ipswich River \#1, with an average of $10.7 \%$ across stream size. HTS exchange had little effect on transport times (all $<1.0 \%$ except Lockwood Brook). Neither $F_{M E D}^{200} S T S$ nor $F_{M E D}^{200} H T S$ was related to contributing area.

[26] Mean storage residence time $\left(T_{\mathrm{STO}}\right)$ : Both mean residence time in STS ( $T_{\mathrm{STO}} \mathrm{STS}$ ) and HTS ( $\left.T_{\mathrm{STO}} \mathrm{HTS}\right)$ showed positive trends with contributing area (Figure 5). A power law regression of the $T_{\mathrm{STO}} \mathrm{STS}$ values was best fit with a power of $0.18\left(R^{2}=0.68\right.$, good residual distribution). The $95 \%$ confidence interval around the regression exponent $( \pm 0.18)$ did not include 1.0, indicating this relationship would not be similarly described by a linear function. The small magnitude of the regression exponent and the fact that 0.0 is included within its $95 \%$ confidence interval indicates that $T_{\mathrm{STO}} \mathrm{STS}$ increased only slightly with contributing area 

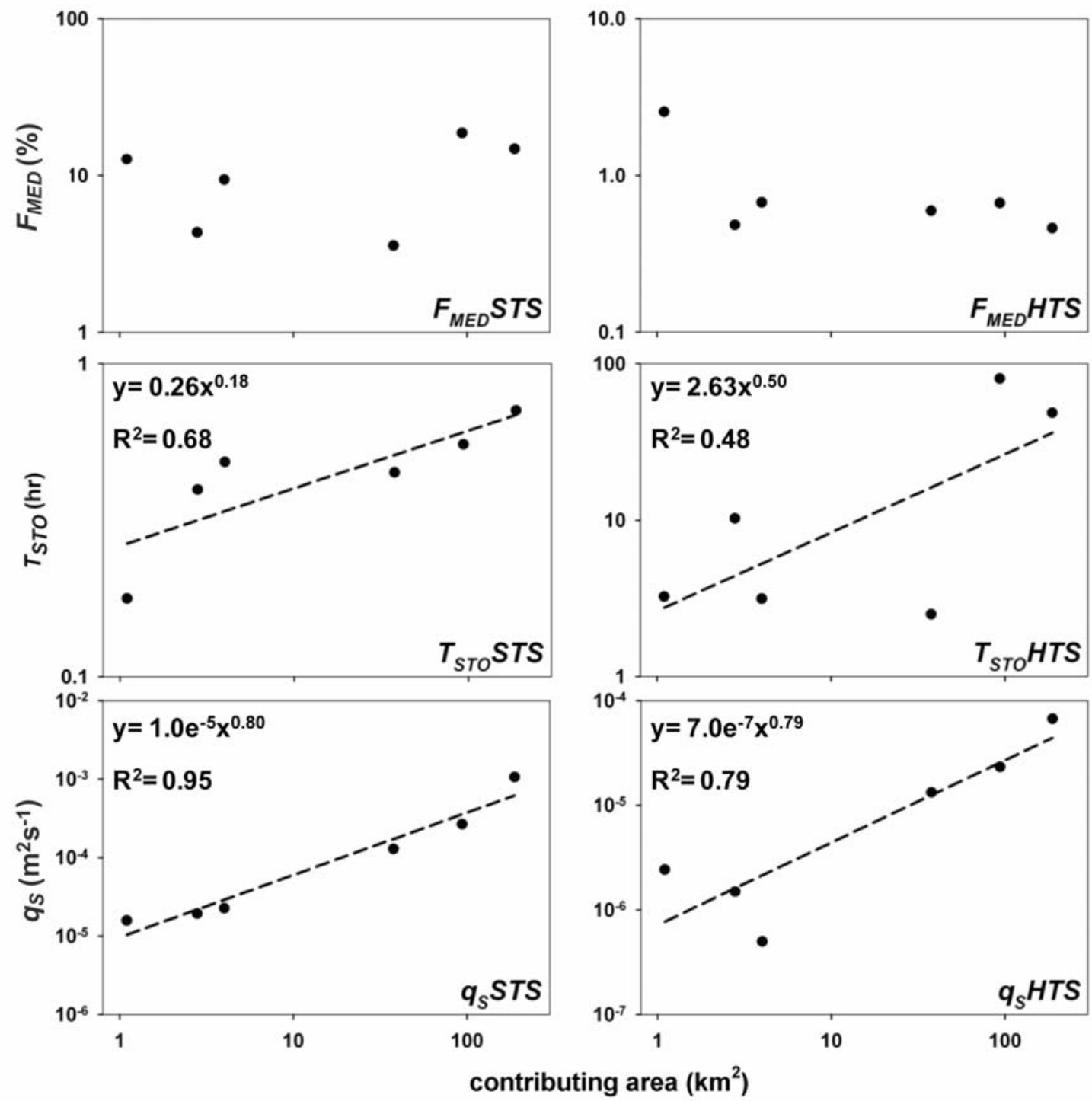

Figure 5. Both the $T_{\mathrm{STO}}$ and $q_{S}$ storage metrics showed trends with contributing area, while $F_{\mathrm{MED}}$ was relatively consistent down the stream continuum for both STS and HTS exchange. Optimal power law regressions are indicated with dashed lines. Relationships between contributing area and $T_{\mathrm{STO}} \mathrm{HTS}_{\text {, }}$ $q_{s}$ STS, and $q_{s}$ HTS may also be described well with linear functions.

though trend may not be statistically significant. Values of $T_{\mathrm{STO}} \mathrm{STS}$ ranged from $0.18 \mathrm{~h}$ at Lockwood Brook to $0.71 \mathrm{~h}$ at Ipswich River \#2. Compared to $T_{\mathrm{STO}} \mathrm{STS}, T_{\mathrm{STO}} \mathrm{HTS}$ increased more with contributing area (power of 0.50 ) but had a weaker relationship $\left(R^{2}=0.48\right.$ with a large $95 \%$ confidence interval \pm 0.72 ) and included a linear fit. The lowest determined $T_{\mathrm{STO}} \mathrm{HTS}$ was found for the Fish Brook injection at $2.5 \mathrm{~h}$, and the largest for Ipswich River \#1 at $80 \mathrm{~h}$. Overall $T_{\text {STO }}$ HTS values were at least an order of magnitude higher than corresponding $T_{\mathrm{STO}} \mathrm{STS}$ estimates.

[27] Mean storage exchange flux $\left(q_{S}\right)$ : The flux between the MC and both STS and HTS showed strong positive relationships with increasing contributing area (Figure 5). A power law fit to the $q_{S}$ STS values had a power of $0.80\left(R^{2}=\right.$ $0.95)$, which included 1.0 within its $95 \%$ confidence interval $( \pm 0.25)$. The values of $q_{S}$ STS ranged from $1.6 \times 10^{-5} \mathrm{~m}^{2} \mathrm{~s}^{-1}$ for Lockwood Brook to $1.1 \times 10^{-3} \mathrm{~m}^{2} \mathrm{~s}^{-1}$ for Ipswich River
\#2. The power law relationship between $q_{S} \mathrm{HTS}$ and contributing area was best fit with a power of 0.79 and $\left(R^{2}=\right.$ $0.79)$ with a large $95 \%$ confidence interval $( \pm 0.56)$. Unlike $q_{S}$ STS, the lowest value for $q_{S} \mathrm{HTS}$ was found not for the stream with the smallest contributing area, but for Sawmill Brook at $5.0 \times 10^{-7} \mathrm{~m}^{2} \mathrm{~s}^{-1}$; whereas the largest value was determined for Ipswich River \#2 at $6.7 \times 10^{-5} \mathrm{~m}^{2} \mathrm{~s}^{-1}$. Evaluations of $q_{S}$ for each storage zone showed the opposite trend of $T_{\mathrm{STO}}$, with STS values being approximately 1 order of magnitude greater than corresponds HTS values.

\subsection{1-SZ Model Results}

[28] Of all the hydraulic parameters we investigated, only $D$ and $A$ are directly comparable between the 1-SZ and 2-SZ models. Optimized 1-SZ estimates of $D$ showed no trend with stream size and were always greater than their 2-SZ counterparts (Table 4). The largest increase from 2-SZ to 


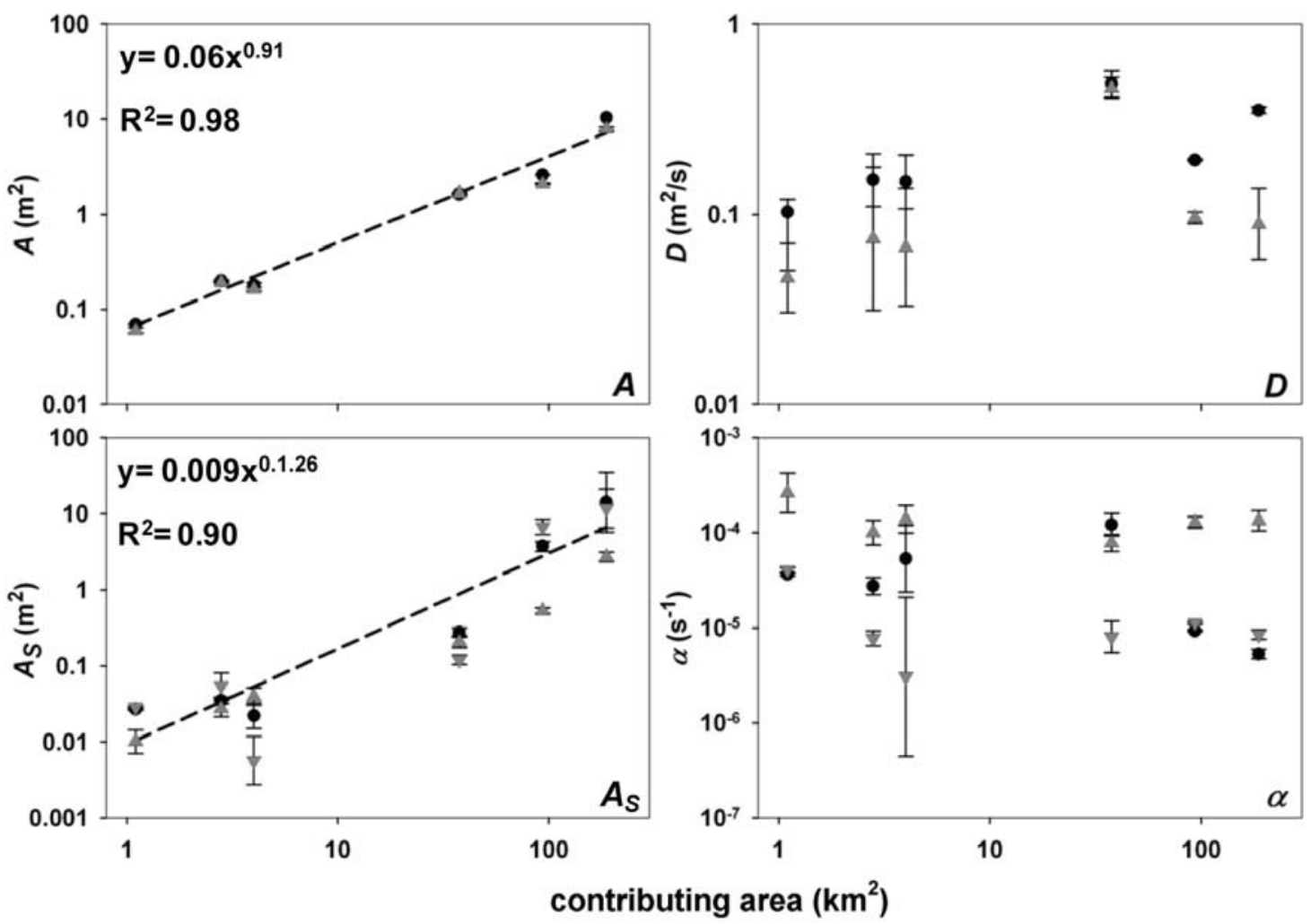

Figure 6. A comparison of 1-SZ and 2-SZ optimized parameter estimates with the 1-SZ values depicted as circles, the general 2-SZ and STS values as $(\mathbf{\Delta})$ and $H T S$ values as $(\boldsymbol{\nabla})$ with parameter $95 \% \mathrm{CI}$ in brackets. Dispersion always increased from the 2-SZ to the 1-SZ model and the 1-SZ storage parameters were variable in comparison to STS and HTS specific parameters. Two 1-SZ parameters showed trends (power law dashed line) similar to the 2-SZ values.

1-SZ estimates of $D$ occurred for Ipswich River \#2 reach $(+300 \%)$ and the smallest for Fish Brook $(+5 \%)$; for the remaining experiments $D$ at least doubled in the 1-SZ models (Figure 6). Confidence intervals were smaller than the estimated parameter for all 1-SZ D estimates, and the CSS estimates were higher than those for the 2-SZ model especially for Ipswich River \#2 $(15 \times)$. The values of $A$ were much more similar between the two models, though 1-SZ estimates were greater in almost every case. As with $D$, the largest change between the 1-SZ and 2-SZ $A$ parameter was for Ipswich River \#2 reach $(+32 \%)$, and the smallest change was for Fish Brook (-2\%) (Figure 6). Analogous to the 2-SZ models, confidence intervals were small, CSS was high for this 1-SZ parameter, and a linear trend was observed with stream size. Optimized values of 1-SZ $A$ were not consistently more or less similar to the original velocity transect estimates compared to the 2-SZ model.

[29] The optimized 1-SZ model estimates for $A_{S}$ (and $A s / A$ ) did not reliably reflect either $A_{\mathrm{STS}}$ or $A_{\mathrm{HTS}}$. In most cases $A_{S}$ fell between the corresponding $A_{\mathrm{STS}}$ and $A_{\mathrm{HTS}}$ values, but for Fish Brook and Ipswich River \#2 $A_{S}$ was larger than either $A_{\mathrm{STS}}$ or $A_{\mathrm{HTS}}$, though less than the combination of the two (Figure 6). Sensitivity to $A_{S}$ was variable, and confidence intervals were small except for Ipswich River \#2. $A_{S}$ showed a positive linear trend basin area, and $A_{S} / A$ showed little trend but was largest for the main stem reaches. Estimates of the 1-SZ $\alpha$ were generally closer to $\alpha_{\mathrm{HTS}}$ than $\alpha_{\text {STS }}$, although for Fish Brook, $\alpha$ was larger than either corresponding 2-SZ term (Figure 6). CSS was low in some cases, but it was never lower than both 2 -SZ exchange terms, and confidence intervals were fairly narrow. No trend in $\alpha$ was observed with stream size, and the smallest values were found for the two main stem reaches.

[30] The 1-SZ transient storage metrics were not reflective of either STS or HTS exchange along the stream network (Figure 7). $F_{M E D}^{200}$ values indicated that exchange with the lumped storage zone increased median transport times appreciably $(\sim 3-5 \%)$ for Lockwood Brook, Sawmill Brook, and Fish Brook, while the $F_{M E D}^{200}$ for Cart Creek and the main stem reaches was insignificant $(<1 \%)$ and virtually identical to corresponding $F_{M E D}^{200} H T S$ estimates. General $T_{\text {STO }}$ estimates decreased slightly with contributing area for the lower-order reaches but, like $T_{\mathrm{STO}} \mathrm{HTS}$, were quite high in the Ipswich River reaches. The strongest trend with contributing area observed for any 1-SZ transient storage metric was found for $q_{S}\left(R^{2}=0.65\right)$, which had a power law exponent of 0.61 . However, the large $95 \%$ confidence interval around the exponent $( \pm 0.62)$ included both a linear trend and no trend at all. Actual $q_{s}$ values fell between their 2-SZ STS and HTS counterparts, except for Fish Brook and Ipswich River \#2.

\section{Discussion}

[31] Our tracer experiments were conducted at approximately the same base flow condition throughout the basin 

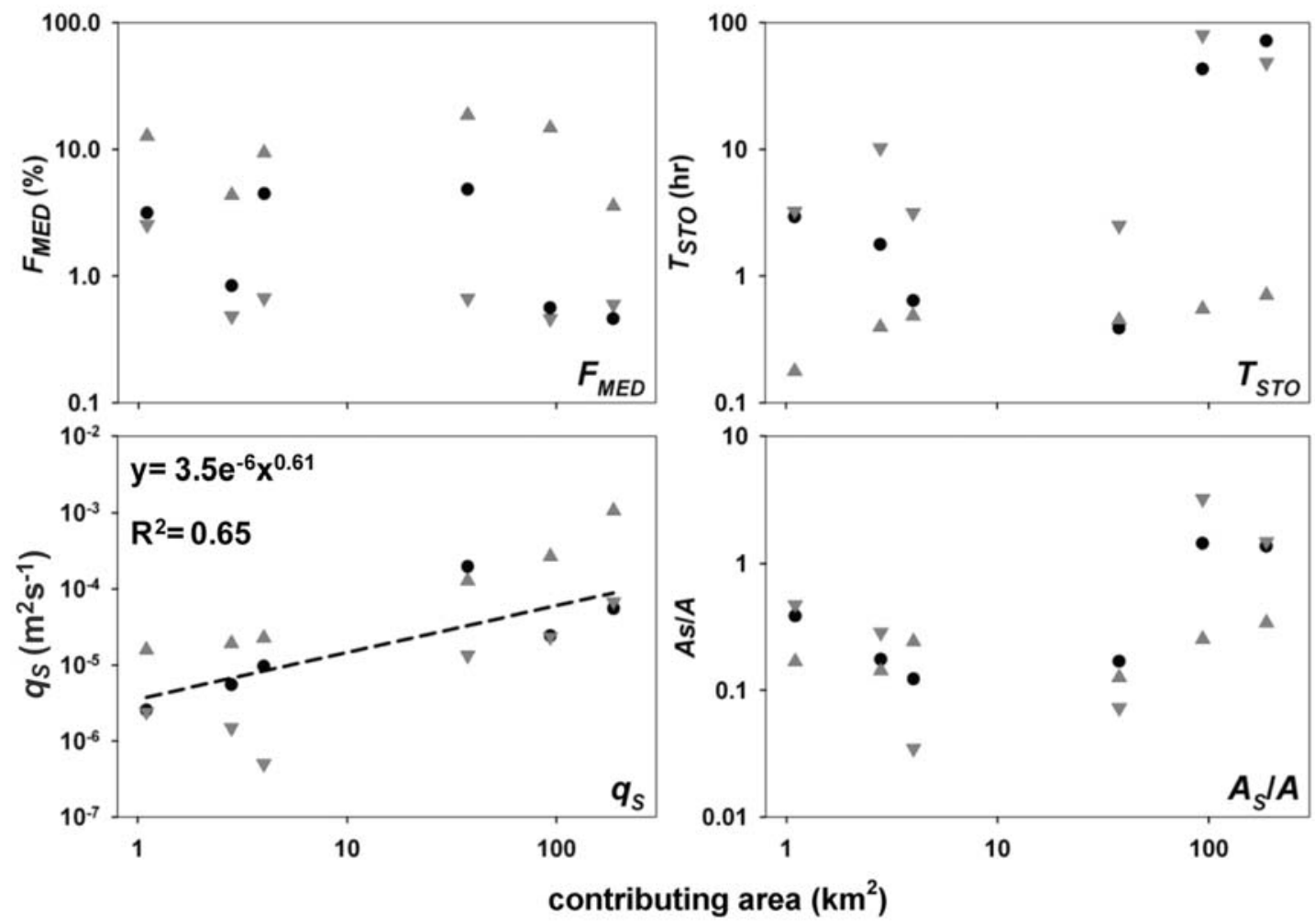

Figure 7. A comparison of 1-SZ and 2-SZ storage metrics with the 1-SZ values depicted as circles, the general 2-SZ and STS values as $(\boldsymbol{\Delta})$ and HTS values as $(\boldsymbol{\nabla}) .1-\mathrm{SZ}$ model $F_{M E D}^{200}$ estimates were generally low and similar to corresponding $F_{M E D}^{200} H T S$ values, Lockwood Brook and the Ipswich River 1-SZ models were likely most sensitive to HTS exchange.

network and were compared by contributing area, a variable we find to be less arbitrary than stream order and more geomorphically relevant than discharge, which varies both spatially and temporally throughout the stream network. Using contributing area as the classifier for stream size indicates context within the stream network and assumes that the morphology of a reach is dictated at least in part by the magnitude of surface land area drained by the stream, an assumption that is validated in this case by the strong positive trends observed in $w, d$, and $A$ with contributing area. Certain geomorphic controls on transient storage are therefore related to contributing area, and these controls influence both STS and HTS exchange. The changes in substrate, slope, and dominant STS type observed for this suite of streams (Table 1) are evidence of such relationships. If streams are compared at the same general basin-wide flow regime, in this case summer base flow, then trends in transient storage dynamics between streams of varying size may be identified. Admittedly, this is a general evaluation as we did not take into account the land use within each catchment, a factor that has been found to influence stream geomorphology and, in turn, transient storage exchange [e.g., Gooseff et al., 2007].

[32] Many watershed characteristics scale according to power law relationships with contributing area. The strong power law relationships between contributing area and discharge, bankfull width, and bankfull depth have long been known [Wolman and Leopold, 1957; Leopold et al., 1964].
More recently, Vianello and D'Agostino [2006] showed that bankfull width of pools and colluvial reaches also show strong power law scaling. Scale invariant relationships have been documented for a variety of stream features ranging from the smallest-scale sedimentary features within a channel, to the lengths of flow paths, to drainage networks themselves [Wolman and Leopold, 1957; Leopold et al., 1964; Wörman et al., 2007]. It has been postulated that because topography can act as a template for the water table and therefore head gradients within the watershed, the power law relationship observed in topography may be applied to surface-groundwater interactions [Wörman et al., 2007]. Power law head gradients may also partially explain how catchments can produce a power law residence time distribution of incoming precipitation [Kirchner et al., 2000]. The potential for transient storage parameters and metrics to show power law scaling in time and/or space was illustrated by a recent study revealing a negative power law relationship between $F_{M E D}^{200}$ and discharge in a small, STSdominated stream [Jin and Ward, 2005]. We explored whether power law functions could explain the relationships we observed between optimal parameter estimates and contributing area along the stream network. If 1.0 was included within the $95 \%$ confidence interval around the best fit power law function exponent, a linear fit was assumed to be sufficient. Although power laws fit many of our data sets well, linear fits were often similar, probably due in part to the limited $(n=6)$ number of data points in each relationship. 


\subsection{Spatial Trends in STS and HTS Parameter Values With Stream Size}

[33] Two basic descriptors of channel hydraulics are mean reach width and depth. For this study these variables showed a strong positive correlation with contributing area. This is consistent with previous investigations, which found strong power law relationships of bankfull widths and depths with contributing area [Wolman and Leopold, 1957; Leopold et al., 1964; Vianello and D'Agostino, 2006] and may provide some insight into the network trends of transient storage dynamics. $A$ is clearly a function of channel width and depth and $A_{S T S}$ is likely to be as well. In turn, $\alpha_{S T S}$ is partially a function of the magnitude and dimension of the interface with the MC.

[34] The optimized model estimates of longitudinal $D$ were relatively low compared to the bulk of reported stream values, which were mostly generated using the 1-SZ model, and they showed no trend downstream. The apparently small magnitude of $D$ may be explained by the base flow conditions at which these injections were performed, because $D$ has been shown to be positively correlated with discharge [D'Angelo et al., 1993; Hart et al., 1999; Jin and $W a r d, 2005]$. In fact, these values of $D$ are appreciable relative to the slow advective transport through these reaches. The lack of any trend indicates that stream size is not the primary driver of $D$, which probably responds most directly to spatial velocity patterns and surface hydraulics within each reach.

[35] Contributing area was a strong indicator of the magnitude of both $A$ and $A_{\mathrm{STS}}$, and sensitivity to these parameters was relatively high with small confidence intervals, indicating strong confidence in these trends based on this experimental data. Power law trends down the stream continuum indicated a linear function could also describe these relationships well. Hyporheic storage zone cross-sectional area, $A_{\mathrm{HTS}}$, showed a weaker linear trend with contributing area than $\operatorname{did} A_{\mathrm{STS}}$. Neither $A_{\mathrm{STS}} / A$ or $A_{\mathrm{HTS}} / A$ had a strong relationship with contributing area, but both ratios were largest for the main stem reaches and may denote an increasing importance of both STS and HTS exchange to biogeochemical processes downstream. This is inconsistent with the results reported by Battin et al. [2008], who found that the normalized storage zone size decreased in larger streams; however, those results were generated using a 1-SZ transport model.

[36] The storage exchange coefficients for STS were very consistent across stream size, indicating that exchange was not affected by the absolute size of the interface with the $\mathrm{MC}$ and/or that size effects were somehow balanced out by other changes in storage zone morphology. The mechanisms of STS generally changed down the continuum from retention in pools, behind debris dams/ boulders, and along shallow channel margins in small streams to storage within weed beds and large backwater areas in large streams. On average, $\alpha_{\text {STS }}$ was an order of magnitude larger than the more variable $\alpha_{\text {HTS, }}$, a result consistent with previous characterizations of STS exchange as significantly faster than HTS exchange [Hall et al., 2002; Gooseff et al., 2004, 2005; Harvey et al., 2005]. These results suggest that one set of corresponding exchange coefficients could be applied to STS for comparable reach lengths throughout the network, therefore simplifying a basin-scale modeling effort.
[37] If the natural stream systems had precisely met the model assumptions, all storage compartments would have had perfect solute mixing. Therefore, if tracer concentrations were falling in the $\mathrm{MC}$, they would always be falling in an adjacent STS zone. A mixing lag was observed between some MC/STS pairs (i.e., concentration falling in the MC and still rising in the adjacent STS zone) resulting from the time it takes to mix the tracer into the STS monitoring point from the MC. This may have affected estimates of $\alpha_{\text {STS }}$ by slowing the apparent exchange with the MC. Additionally, as with $A_{\mathrm{HTS}}$, low model sensitivity suggests $\alpha_{\mathrm{HTS}}$ is uncertain and may hamper the utility of these results.

[38] There was generally low sensitivity to most HTS parameters during these reach scale 2-SZ modeling experiments. Information collected from the late time tracer $\mathrm{MC}$ BTC tail may be compromised by changes in background conductivity and reasonable tracer detection limits, yielding poorer parameter estimates. Experimental reach lengths longer than those we used would likely yield more information regarding HTS dynamics but would result in reduced STS sensitivity. Fundamentally, the model may not represent observed HTS exchange adequately in using an exponential function to describe residence time distribution, which may in actuality follow a power law [Haggerty et al., 2002; Gooseff et al., 2003; Cardenas et al., 2008]. Unfortunately it is not practical to collect reach-representative point measurements of the subsurface, in part because there is such a high degree of spatial variability in hyporheic flow paths [Harvey and Wagner, 2000]. In contrast reach representative STS zones are identified through the velocity survey and can contain internal circulation that results in some mixing, rendering point measurements more representative of the general zone condition. As data collected from representative STS locations were used during the optimization process and HTS data were not, and the more rapid STS exchange likely had a more pronounced affect on the MC solute BTC than HTS exchange, STS sensitivities were much higher, and estimates were more confident. Yet both surface and hyporheic storage results are useful, especially given that relatively few studies have attempted to discriminate between STS and HTS exchange with the MC.

[39] We expect the downstream scaling of transient storage model parameters to be nonadditive because the transient storage model parameter estimates have been shown to be dependent on experimental reach lengths [Wagner and Harvey, 1997; Harvey and Wagner, 2000] possibly resulting from tracer sensitivity, heterogeneity, and emergent processes along increasing stream lengths. We can make an assessment of how transient storage dynamics change between reaches of comparable length (optimal DaI range) down the stream continuum, therefore comparing reaches within the network, not network length flowpaths. Using this reach definition, spatial trends were evident for many model parameters, while others remained remarkably consistent across stream size.

[40] A reach length which provides enough, but not too much, exchange between the stream $\mathrm{MC}$ and transient storage to yield the maximum amount of information regarding storage dynamics should optimally generate a DaI evaluation of 0.1-10.0. Attaining an optimal DaI range based on reach length is complicated by the simultaneous investigation of both STS and HTS with a solute tracer. As 
we expect much faster exchange between the MC and STS than between the MC and HTS, the STS DaI will be larger over the same experimental reach, especially because the exchange coefficient exerts more influence on DaI than does the size of the storage zone. If the goal of a study is to determine an experimental reach length that provides representative estimates of exchange with both STS and HTS, a concern may often be sampling enough exchange with HTS using the solute tracer to provide adequate information about that process while not diminishing STS sensitivity with too much exchange. Therefore, determining an experimental reach length that is ideal for investigating in-stream and subsurface storage simultaneously may be difficult. This dilemma is illustrated by the case of Lockwood Brook and the main stem reaches where HTS exchange was adequate to meet the low end of DaI criteria, yet STS exchange exceeded the optimal DaI range. Conversely, a simple evaluation using the 1-SZ model parameters alone put all reaches within this optimal DaI range. Although some reach lengths in our study may have been excessive for estimating STS parameters as evaluated by the DaI, STS sensitivity was generally much higher than corresponding HTS parameter sensitivity (as evaluated by UCODE_2005), probably as a result of the additional field data collected regarding STS and integrated into the modeling process.

\subsection{Spatial Trends in STS and HTS Storage Metrics With Stream Size}

[41] Transient storage dynamics are made more tangible when evaluated with storage metrics, which quantify the influence of transient storage on stream transport and biogeochemical processes. We observed no downstream trends in $F_{M E D}^{200} S T S$, as exchange with STS had an appreciable effect on median transport time at all points along the stream continuum. In fact the average $F_{M E D}^{200} S T S$ for this suite of stream reaches $(10.7 \%)$ corresponds to the 78 th percentile of the range of $F_{M E D}^{200}$ values calculated for 53 different stream reaches (using 1-SZ model parameters) by Runkel [2002]. This finding contradicts the common assumption that the importance of transient storage exchange decreases downstream. $F_{M E D}^{200} H T S$ values also showed no spatial trends, but unlike STS, HTS exchange had a consistently minor effect on median transport times. The average $F_{M E D}^{200} H T S$ value corresponded to approximately the 20th percentile of the values reported by Runkel [2002]. This clearly suggests that STS exchange is more influential to actual transport times across these basins, but this evidence alone does not necessarily indicate that STS is more influential to biogeochemical processes, in part because residence times are relatively short.

[42] To further investigate the relationship between transient storage and biogeochemical cycling, we need to know, in addition to storage zone-specific reaction rates, how much water is going into both STS and HTS and how long it remains. The positive trend observed in $T_{\mathrm{STO}} \mathrm{STS}$ provides the most convincing evidence (aside from the mean $w$ and $d$ ) that a power law describes the spatial relationship because the exponent was small $(0.18)$ and well outside the $95 \%$ confidence interval for a linear relationship (Figure 5). The values of $T_{\mathrm{STO}} \mathrm{STS}$ were low for the small streams but increased to $0.7 \mathrm{~h}$ for the largest stream, suggesting STS may become both hydrologically and biogeochemically more important to stream processes downstream. As with the $A_{\mathrm{STS}}$ parameter, this is not consistent with the synthesis of Battin et al. [2008], which found that (1-SZ) $T_{\text {STO values }}$ generally decreased with increasing stream size. This discrepancy may be due in part to the differences in the lumping of transient storage processes that occurs in the 1-SZ model versus the separation of effects in the $2-\mathrm{SZ}$ model and/or to the fact that our experiments all took place at low flow. During the summer low-flow period, channel width does not significantly change with declining flow at a site, and as downstream systems have a high width-to-depth ratio, we may expect more relative surficial storage downstream at low-flow conditions than at higher-flow conditions.

[43] $T_{\text {STO }}$ HTS values were much higher and increased linearly at a much faster rate with stream size than corresponding $T_{\mathrm{STO}} \mathrm{STS}$ values, suggesting that there is ample opportunity for solutes that enter HTS to be biogeochemically altered. The strong disparity between STS and HTS residence time (STS short, HTS long) is likely a dominant factor in determining whether surficial or subsurface flow paths exert greater control on nutrient retention within the basin, potentially trumping the disparity in storage exchange flux (STS high, HTS low). However, there is also the possibility that STS zones retain (net assimilation) nutrients, while HTS zones are dominated by remineralization processes that provide nutrient inputs (regeneration as opposed to retention) to the main channel. The extremely long estimates of $T_{\mathrm{STO}} \mathrm{HTS}$ for the main stem reaches probably result from exchange processes that are on the outer limit of detection with stream tracers [Harvey and Wagner, 2000], and this long retention time is similar to that determined for an eighth-order river [Fernald et al., $2001]$.

[44] As $\alpha_{\text {STS }}$ was fairly consistent across stream size, changes in $q_{S}$ STS $\left(=\alpha_{\mathrm{STS}} A\right.$ ) were primarily controlled by $A$ and showed a strong linear relationship with stream size. The distribution of $q_{S}$ HTS with stream size was more variable, and the positive relationship with contributing area is questionable as the first three values indicated a declining trend. The flux through STS was generally at least an order of magnitude greater than the corresponding HTS flux and increased at a faster rate with increasing stream size because the values of $\alpha_{\text {STS }}$ were much larger. The possible trade-off between storage residence time and storage exchange flux is unclear in terms of which storage zone has the greatest influence on stream chemistry, though estimating storage zone-specific reaction rates would clarify this relationship.

[45] By comparing STS and HTS specific exchange across stream size at the same general base flow condition, several trends have been identified that may be indicative of the broad shift in dynamics with increasing stream size. However, these relationships do not provide a good approximation of the range of flow conditions expected at any one location through time. For example, areas downstream of channel obstructions close to the thalweg that serve as STS during low flow may be incorporated into MC flow at higher discharge, but at the same time lateral areas that were not well connected to the channel at low discharge can be activated and serve as STS storage during higher discharge events. Therefore, we may expect these base flow trends to change significantly or disappear altogether at different flow conditions. As the bulk of dissolved nutrients 
are exported to the coast at high discharge, an evaluation of transport and longitudinal changes in transient storage across the range of flow conditions (i.e., at-a-site relationships) is also crucial to understanding the retentive nature of the basin, but it is difficult to achieve using current technology (or techniques).

[46] One of the main goals of this investigation was to better inform an Ipswich River basin-scale model regarding gradients in transient storage dynamics with stream size. Although we have documented several trends based on this suite of reach scale experiments, bias exists in the stream reaches selected for study. Out of necessity we chose sites that were relatively channelized, due to the nature of both conservative and coupled nonconservative (not included here) tracer methods. Much of the Ipswich River network does not fit into this category because its low gradient generates marshy areas and very high width-to-depth ratios, features that are expanded and intensified by pervasive beaver activity. The variability in our data set does not encompass nonchannelized features, which are represented in the stream network of the Ipswich River basin. Further work should focus on addressing these nonchannelized stream features.

\subsection{Comparison of 1-SZ Versus 2-SZ Modeling Across Stream Size}

[47] One major criticism of the 1-SZ transport model is that the general storage terms may be sensitive to either STS exchange, HTS exchange, or some combination of the two, essentially yielding an ambiguous description of the system. As solute transport modeling is biased toward fastexchanging processes, comparisons of general storage estimates across varied flow regimes and basin type further compound this problem [Harvey and Wagner, 2000; Edwardson et al., 2003]. Therefore, although the 1-SZ model terms may indeed represent either STS or HTS alone in certain systems at specific flow regimes, when we attempt to compare data sets with differing variables such as stream size, discharge, and velocity to identify trends we may in fact be comparing a shift in sensitivity to different storage exchange processes. As a result, variability in broad-scale synthesis of transient storage properties with stream size is huge [e.g., Battin et al., 2008].

[48] A comparison of the 1-SZ and 2-SZ modeling results of the same reach scale experiments based on the $R^{2}$ of the simulated and observed boundary MC BTCs for each reach revealed that the two models produced similar simulations of MC solute dynamics. Two parameters, $A$ and $D$, are directly comparable between the two models. The 1-SZ values of $A$ were similar to estimates generated with the 2-SZ model and had an identical relationship with increasing stream size. The consistent difference between the two model simulations applied to each reach was that 1-SZ estimates of $A$ were almost always larger than 2-SZ estimates, and this difference was substantial for the two main stem reaches. A similar but greatly exaggerated relationship exists for $D$, whose $1-\mathrm{SZ}$ estimates were more than double their 2-SZ counterparts for every reach except Fish Brook. The 1-SZ model may be partially attributing effects of exchange with STS to advection/dispersion (more likely the latter), potentially because some of this storage exchange takes place on a timescale similar to the process of longitudinal dispersion.

[49] Many studies have assumed the lumped storage terms of the 1-SZ model to principally represent HTS [Valett et al., 1996; Morrice et al., 1997; Haggerty et al., 2002; McKnight et al., 2004]. We have shown this assumption is likely not valid, at least for streams at base flow in this coastal basin. This may partially explain why previous transient storage estimates have poorly explained biogeochemical activity such as denitrification rate [Mulholland et al., 2008]. The 1-SZ $A_{S}$ values were variable in terms of providing a closer match to $A_{\mathrm{HTS}}$ or $A_{\mathrm{STS}}$. For Lockwood Brook and the two main stem reaches, CSS and estimated values of $A_{S}$ closely resembled estimates of $A_{\mathrm{HTS}}$, though this pattern seemed to reverse for the mid-size streams. This was mirrored by the 1-SZ $\alpha$ and all 1-SZ storage metrics, which closely matched $A_{\text {HTS }}$ for the smallest and largest reaches but differed for the others. Interestingly, Fish Brook seems to be an outlier for all of these patterns. There, the $1-\mathrm{SZ} A_{S}$ and $\alpha$ were quite close to the STS terms, and the $D$ and $A$ estimates have negligible change between the two models. This suggests that when the 1-SZ terms are more sensitive to STS exchange than HTS exchange, less overlap exists between storage exchange and longitudinal dispersion.

[50] Interestingly, 1-SZ $F_{M E D}^{200}$ evaluations were generally negligible, and always much lower than corresponding $F_{M E D}^{200} S T S$ estimates, meaning that in most of our 1-SZ models the longitudinal dispersion parameter was almost completely responsible for any shift in tracer mass toward later time. But when observed STS behavior was incorporated into the 2-SZ modeling process, estimates of $D$ fell sharply, again possibly resulting from these processes occurring on similar timescales. This comprises a fundamental difference in how we describe transport over the same stream reach compared to previous studies. Our more realistic description of STS exchange and our separation of exchange from longitudinal dispersion are relevant to those interested in discriminating surface from subsurface controls on biogeochemical processing.

\section{Conclusions}

[51] A 2-SZ transient storage model was used to simulate solute injections in six stream reaches of varying contributing area located within two similar, adjacent coastal basins in order to evaluate patterns in transient storage dynamics down the stream continuum. Overall model sensitivity to STS parameters was high, and confidence intervals for STS parameters were small, while HTS parameters had lower sensitivities and larger confidence intervals around the optimized estimates. We found positive relationships between the optimized $A, A_{\mathrm{STS}}$, and $A_{\mathrm{HTS}}$ parameters with contributing area, yet site-specific storage zone size normalized to the MC had weak correlation with contributing area; however, we found no evidence of a decrease in this ratio downstream as has been shown in previous work. Additionally, no trend was evident between $D, \alpha_{\text {STS }}$, or $\alpha_{\text {HTS }}$ and stream size, and $\alpha_{\text {STS }}$ was generally an order of magnitude higher than corresponding $\alpha_{\text {HTS }}$. Absolute values of $D$ were generally small compared to other systems, though they were relatively high compared to advection during the low-flow period in which our study took place. 
[52] Mean residence time in STS may follow a slightly positive power law relationship with contributing area, whereas $T_{\text {STO }}$ HTS increased strongly downstream. The related $q_{S}$ STS showed a strong positive linear trend with increasing stream size and was at least an order of magnitude greater than the corresponding $q_{S} \mathrm{HTS}$, which generally increased with stream size, although this trend was not as strong. Finally, $F_{M E D}^{200}$ evaluations of both STS and HTS indicated that, overall, STS exchange was much more influential to median reach travel times than was HTS exchange, and both $F_{M E D}^{200} S T S$ and $F_{M E D}^{200} H T S$ showed little trend with stream size. Generally the influence of STS exchange on biogeochemical processes likely increases down this stream continuum, whereas HTS conditions promote processing at all scales because residence time in HTS is long. However, exchange with HTS flow paths is slow and inconsequential to bulk solute transport.

[53] When 2-SZ results separating STS and HTS dynamics were contrasted with general 1-SZ modeling estimates from the same experiments, some notable differences were evident. $D$ was dramatically larger in the $1-\mathrm{SZ}$ model than in the 2-SZ model, potentially because longitudinal dispersion takes place on a timescale similar to STS exchange. Therefore, when STS-specific solute dynamics are not included into the modeling process, $D$ may be inflated to fit the observed MC boundary BTC. Additionally, the general storage terms of the 1-SZ model did not consistently reflect either STS or HTS exchange across stream size within this basin. This should serve as cautionary evidence against the assumption that the 1-SZ model describes either STS or HTS exchange alone, even in systems that appear to be dominated by one storage compartment.

[54] Dynamics of STS and HTS through space and time are governed by a complex combination of geologic, hydrologic, and hydraulic factors. We have shown that several reach-scale transient storage processes may follow spatial trends (linear, power law, or consistency) with contributing area at base flow conditions within this coastal watershed. Whereas the consequences of storage zonespecific dynamics for biogeochemical processing have yet to be quantified, the estimation of separate STS and HTS hydraulics is an important step in that direction.

[55] Acknowledgments. Many thanks to K. Morkeski, B. Jackson, R. Stewart, N. Morse, M. Weaver, T. Harms, and G. Gettel for field work help. We would like to thank D. Benson and E. Poeter for their reviews of an early version of this manuscript. Also thank you to the Massachusetts towns of Boxford, Burlington, Middleton, Byfield, and North Reading for site access and the Plum Island Ecosystems LTER for logistical support. This material is based upon work supported by NSF grants DEB 06-14350, BCS-0709685, and OCE-0423565. Any opinions, findings, and conclusions or recommendations expressed in this material are those of the author(s) and do not necessarily reflect the views of the National Science Foundation.

\section{References}

Alexander, R. B., R. A. Smith, and G. E. Schwarz (2000), Effect of stream channel size on the delivery of nitrogen to the Gulf of Mexico, Nature, 403, 758-761, doi:10.1038/35001562.

Battin, T. J., L. A. Kaplan, S. Findlay, C. S. Hopkinson, E. Marti, A. I. Packman, J. D. Newbold, and F. Sabater (2008), Biophysical controls on organic fluxes in fluvial networks, Nat. Geosci., 1, 95-100, published online, doi:10.1038/ngeo101.
Bernot, M. J., and W. K. Dodds (2005), Nitrogen retention, removal, and saturation in lotic ecosystems, Ecosystems (N.Y.), 8, 442-453, doi:10.1007/s10021-003-0143-y.

Briggs, M. A., M. N. Gooseff, C. D. Arp, and M. A. Baker (2009), A Method for estimating surface transient storage parameters for streams with concurrent hyporheic storage, Water Resour. Res., 45, W00D27, doi:10.1029/ 2008WR006959.

Cardenas, M. B., J. L. Wilson, and R. Haggerty (2008), Residence time of bedform-driven hyporheic exchange, Adv. Water Resour., 31, 13821386, doi:10.1016/j.advwatres.2008.07.006.

Carlozzi, C., K. King, and W. Newbold (1975), Ecosystems and Resources of the Massachusetts Coast, 68 pp., Mass. Coastal Zone Manage. Program, Boston.

Choi, J., J. W. Harvey, and M. H. Conklin (2000), Characterizing multiple timescales of stream and storage zone interaction that affect solute fate and transport in streams, Water Resour. Res., 36(6), 1511-1518, doi:10.1029/2000WR900051.

D’Angelo, D. J., J. R. Webster, S. V. Gregory, and J. L. Meyer (1993), Transient storage in Appalachian and Cascade mountain streams as related to hydraulic characteristics, J. N. Am. Benthol. Soc., 12, 223-235.

Darracq, A., and G. Destouni (2005), In-stream nitrogen attenuation: Model-aggregation effects and implications for coastal nitrogen impacts, Environ. Sci. Technol., 39, 3716-3722, doi:10.1021/es049740o.

Edwardson, K. J., W. B. Bowden, C. Dahm, and J. Morrice (2003), The hydraulic characteristics and geochemistry of hyporheic and parafluvial zones in Arctic tundra streams, north slope, Alaska, Adv. Water Resour., 26, 907-923, doi:10.1016/S0309-1708(03)00078-2.

Fernald, A. G., P. J. Wigington Jr., and D. H. Landers (2001), Transient storage and hyporheic flow along the Willamette River, Oregon: Field measurements and model estimates, Water Resour. Res., 37(6), 16811694, doi:10.1029/2000WR900338.

Gooseff, M. N., and B. L. McGlynn (2005), A stream tracer technique employing ionic tracers and specific conductance data applied to the Maimai catchment, New Zealand, Hydrol. Process., 19(13), 2491-2506.

Gooseff, M. N., S. M. Wondzell, R. Hagerty, and J. Anderson (2003), Comparing transient storage modeling and residence time distribution (RTD) analysis in gemorphologically varied reaches in the Lookout Creek basin, Oregon, USA, Adv. Water Resour., 26(9), 925-937, doi:10.1016/S0309-1708(03)00105-2.

Gooseff, M. N., D. M. McKnight, R. L. Runkel, and J. H. Duff (2004), Denitrification and hydrologic transient storage in a glacial meltwater stream, McMurdo Dry Valley, Antarctica, Limnol. Oceanogr., 49(5), 1884-1895.

Gooseff, M., J. LaNier, R. Haggerty, and K. Kokkeler (2005), Determining in-channel (dead zone) transient storage by comparing solute transport in a bedrock channel-alluvial channel sequence, Oregon, Water Resour. Res., 41, W06014, doi:10.1029/2004WR003513.

Gooseff, M. N., R. O. Hall Jr., and J. L. Tank (2007), Relating transient storage to channel complexity in streams of varying land use in Jackson Hole, Wyoming, Water Resour. Res., 43, W01417, doi:10.1029/ 2005WR004626.

Haggerty, R., S. M. Wondzell, and M. A. Johnson (2002), Power-law residence time distribution in the hyporheic zone of a 2 nd -order mountain stream, Geophys. Res. Lett., 29(13), 1640, doi:10.1029/2002GL014743.

Hall, R. O., E. S. Bernhardt, and G. E. Likens (2002), Relating nutrient uptake with transient storage in forested mountain streams, Limnol. Oceanogr., 47(1), 255-265.

Hart, D. R., P. J. Mulholland, E. R. Marzolf, D. L. DeAngelis, and S. P. Hendricks (1999), Relationships between hydraulic parameters in a small stream under varying flow and seasonal conditions, Hydrol. Process., 13, 1497-1510, doi:10.1002/(SICI)1099-1085(199907)13:10<1497::AIDHYP825>3.0.CO;2-1.

Harvey, J. W., and K. E. Bencala (1993), The effects of streambed topography on surface-subsurface water exchange in mountain catchments, Water Resour. Res., 29(1), 89-98, doi:10.1029/92WR01960.

Harvey, J. W., and B. J. Wagner (2000), Quantifying hydrologic interactions between streams and their subsurface hyporheic zones, in Streams and Ground Waters, edited by J. B. Jones and P. J. Mulholland, pp. 3-44, Academic, San Diego, doi:10.1016/B978-012389845-6/50002-8.

Harvey, J. W., B. J. Wagner, and K. E. Bencala (1996), Evaluating the reliability of the stream tracer approach to characterize stream-subsurface water exchange, Water Resour. Res., 32(8), 2441-2451, doi:10.1029/ 96WR01268.

Harvey, J. W., J. E. Saiers, and J. T. Newlin (2005), Solute transport and storage mechanisms in wetlands of the Everglades, south Florida, Water Resour. Res., 41, W05009, doi:10.1029/2004WR003507. 
Hill, M. C., and C. R. Tiedeman (2007), Effective Groundwater Model Calibration With Analysis of Data, Sensitivities, Predictions, and Uncertainty, John Wiley, Hoboken, N. J.

Jin, H., and G. M. Ward (2005), Hydraulic characteristics of a small coastal plain stream of the southeastern United States: Effects of hydrology and season, Hydrol. Process., 19, 4147-4160, doi:10.1002/hyp.5878.

Kasahara, T., and S. M. Wondzell (2003), Geomorphic controls on hyporheic exchange flow in mountain streams, Water Resour. Res., 39(1), 1005, doi:10.1029/2002WR001386.

Kirchner, J. W., X. Feng, and C. Neal (2000), Fractal stream chemistry and its implications for contaminant transport in catchments, Nature, 403, 524-527, doi:10.1038/35000537.

Leopold, L. B., M. G. Wolman, and J. P. Miller (1964), Fluvial Processes in Geomorphology, 522 pp., Freeman, San Francisco.

Lindgren, G. A., and G. Destouni (2004), Nitrogen loss rates in streams: Scale-dependence and up-scaling methodology, Geophys. Res. Lett., 31, L13501, doi:10.1029/2004GL019996.

McKnight, D. M., R. L. Runkel, C. M. Tate, J. H. Duff, and D. L. Moorhead (2004), Inorganic $\mathrm{N}$ and $\mathrm{P}$ dynamics of Antarctic glacial meltwater streams as controlled by hyporheic exchange and benthic autotrophic communities, J. N. Am. Benthol. Soc., 23(2), 171-188, doi:10.1899/0887-3593 (2004)023<0171:INAPDO >2.0.CO;2.

Montgomery, D. R., and J. M. Buffington (1997), Channel-reach morphology in mountain drainage basins, Geol. Soc. Am. Bull., 109(5), 596-611, doi:10.1130/0016-7606(1997)109<0596:CRMIMD>2.3.CO;2.

Morrice, J. A., H. M. Valett, C. N. Dahm, and M. E. Campana (1997), Alluvial characteristics, ground-surface water exchange and hydrological retention in headwater streams, Hydrol. Process., 11, 253-267, doi:10.1002/(SICI)1099-1085(19970315)11:3<253::AID-HYP439>3.0. $\mathrm{CO} ; 2-\mathrm{J}$.

Mulholland, P. J., et al. (2008), Stream denitrification across biomes and its response to anthropogenic nitrate loading, Nature, 452, 202-205, doi:10.1038/nature06686.

Payn, R. A., M. N. Gooseff, D. A. Benson, O. A. Cirpka, J. P. Zarnetske, W. B. Bowden, J. P. McNamara, and J. H. Bradford (2008), Comparison of instantaneous and constant-rate stream tracer experiments through non-parametric analysis of residence time distributions, Water Resour. Res., 44, W06404, doi:10.1029/2007WR006274.

Poeter, E. P., M. C. Hill, E. R. Banta, S. Mehl, and S. Christensen (2005), UCODE_2005 and Six Other Computer Codes for Universal Sensitivity Analysis, Calibration, and Uncertainty Evaluation: U.S. Geological Survey Techniques and Methods, 6-A11, 2839.

Runkel, R. L. (1998), One-Dimensional Transport with Inflow and Storage (OTIS): A Solute Transport Model for Streams and Rivers, 73 pp., U.S. Geological Survey Water-Resources Investigation Report 98-4018, Denver.
Runkel, R. L. (2002), A new metric for determining the importance of transient storage, J. N. Am. Benthol. Soc., 21, 529-543, doi:10.2307/ 1468428.

Schumm, S. A. (1977), The Fluvial System, Wiley-Interscience, New York.

Thackston, E. L., and K. B. Schnelle (1970), Predicting effects of dead zones on stream mixing, J. Sanit. Engrg. Div., 96, 319-331.

Valett, H. M., J. A. Morrice, C. N. Dahm, and M. E. Campana (1996), Parent lithology, groundwater-surface water exchange and nutrient retention in headwater streams, Limnol. Oceanogr., 41(2), 333-345.

Vannote, R. L., G. W. Minshall, K. W. Cummins, J. R. Sedell, and C. E. Cushing (1980), The river continuum concept, Can. J. Fish. Aquat. Sci., 37, 130-137, doi:10.1139/f80-017.

Vianello, A., and V. D'Agostino (2006), Bankfull width and morphological units in an alpine stream of dolomites (Northern Italy), Geomorphology, 83, 266-281, doi:10.1016/j.geomorph.2006.02.023.

Wagner, B. J., and J. W. Harvey (1997), Experimental design for estimating parameters of rate-limited mass transfer: Analysis of stream tracer studies, Water Resour. Res., 33(7), 1734-1741, doi:10.1029/ 97WR01067.

Weitbrecht, V., S. A. Socolofsky, and G. H. Jirka (2008), Experiments on mass exchange between groin fields and main stream in rivers, $J$. Hydraul. Eng., 134(2), 173-183, doi:10.1061/(ASCE)0733-9429(2008)134:2 (173).

Wollheim, W. M., C. J. Vörösmarty, B. J. Peterson, S. P. Seitzinger, and C. S. Hopkinson (2006), Relationship between river size and nutrient removal, Geophys. Res. Lett., 33, L06410, doi:10.1029/2006GL025845.

Wolman, M. G., and L. B. Leopold (1957), River Floodplains: Some Observations on Their Formation. Geological Survey Professional Paper, 282-C, U.S. Government Printing Office, Washington, D. C.

Wörman, A., P. I. Packman, L. Marklund, J. W. Harvey, and S. H. Stone (2007), Fractal topography and subsurface water flows from fluvial bedforms to the continental shield, Geophys. Res. Lett., 34, L07402, doi:10.1029/2007GL029426.

M. A. Briggs, Hydrologic Science and Engineering Program, Colorado School of Mines, Golden, CO 80401, USA. (martybriggs.1@gmail.com)

M. N. Gooseff, Department of Civil and Environmental Engineering, Pennsylvania State University, University Park, PA 16802, USA.

C. S. Hopkinson, Department of Marine Sciences, University of Georgia, Athens, GA 30602, USA.

K. Morkeski and B. J. Peterson, Ecosystems Center, Marine Biological Laboratory, Woods Hole, MA 02543, USA.

W. M. Wollheim, Institute for the Study of Earth, Oceans, and Space, University of New Hampshire, Durham, NH 03824, USA. 